\title{
Diagnosing Human-Induced Dynamic and Thermodynamic Drivers of Extreme Rainfallo
}

\author{
LINYIN CHENG \\ University of Colorado, Cooperative Institute for Research in Environmental Sciences, and Physical Sciences \\ Division, NOAA/Earth System Research Laboratory, Boulder, Colorado \\ MARTIN HOERLING \\ NOAA/Earth System Research Laboratory, Physical Sciences Division. Boulder, Colorado \\ LESLEY SMITH AND JON EISCHEID \\ University of Colorado, Cooperative Institute for Research in Environmental Sciences, and Physical Sciences \\ Division, NOAA/Earth System Research Laboratory, Boulder, Colorado
}

(Manuscript received 5 January 2017, in final form 16 October 2017)

\begin{abstract}
Factors responsible for extreme monthly rainfall over Texas and Oklahoma during May 2015 are assessed. The event had a return period of at least 400 years, in contrast to the prior record, which was roughly a 100-yr event. The event challenges attribution science to disentangle factors because it occurred during a strong El Niño, a natural pattern of variability that affects the region's springtime rains, and during the warmest global mean temperatures since 1880. Effects of each factor are diagnosed, as is the interplay between El Niño dynamics and human-induced climate change.

Analysis of historical climate simulations reveals that El Niño was a necessary condition for monthly rains to occur having the severity of May 2015. The model results herein further reveal that a 2015 magnitude event, whether conditioned on El Niño or not, was made neither more intense nor more likely to be due to humaninduced climate change over the past century.

The intensity of extreme May rainfall over Texas and Oklahoma, analogous to the 2015 event, increases by roughly $5 \%$ by the latter half of the twenty-first century. No material changes occur in either El Niño-related teleconnections or in overall atmospheric dynamics during extreme May rainfall over the twenty-first century. The increased severity of Texas/Oklahoma May rainfall events in the future is principally due to thermodynamic driving, although much less than implied by simple Clausius-Clapeyron scaling arguments given a projected $23 \%$ increase in atmospheric precipitable water vapor. Other thermodynamic factors are identified that act in opposition to the increase in atmospheric water vapor, thereby reducing the effectiveness of overall thermodynamic driving of extreme May rainfall changes over Texas and Oklahoma.
\end{abstract}

\section{Introduction}

A challenge in determining human-induced impacts on extreme weather is diagnosing both dynamic and thermodynamic consequences of climate change on event statistics. Dynamical changes in atmospheric

Supplemental information related to this paper is available at the Journals Online website: https://doi.org/10.1175/JCLI-D-160919.s1.

Corresponding author: Linyin Cheng, linyin.cheng@noaa.gov circulation associated with anthropogenic forcing are generally less well understood than thermodynamic changes (e.g., Shepherd 2014), in part owing to the lower detectability of the former compared to the latter. One perspective therefore proposes to treat the dynamics as being largely unaffected by climate change, and to isolate only how an event is affected by changes in thermodynamics (Trenberth et al. 2015). Another perspective, which takes some account of dynamics, is to identify an atmospheric circulation pattern having event relevance and diagnose the interplay between that circulation and climate change in the event's production (e.g., Christidis 
and Stott 2015). Further, when large data volumes are available, accounting can also be made of changes in the atmospheric circulation itself, permitting one to estimate the separate contributions of dynamic and thermodynamic effects on extreme weather events (Vautard et al. 2016).

Here we assess how climate change affected an extreme rainfall event using an approach similar to that of Christidis and Stott (2015) that in addition separately examines the effectiveness of changes in dynamic and thermodynamic drivers. We apply a framework for interpreting our results following Shepherd (2016), who discusses the concept of dynamically conditioned causes for extremes in a changing climate. The principal data used in our study to apply such a formalism are coupled ocean-atmosphere simulations of global climate spanning 1920-2100, described in section 2. Our approach does not involve the construct of "factual" and "counterfactual" climates as employed in some event attribution studies based on atmospheric model experiments (e.g., Pall et al. 2011; Massey et al. 2015; Vautard et al. 2016) but rather involves sampling of time slices from the coupled model's transient simulation. It is, however, reliant on statistics of a particular model (albeit of a large 40-member ensemble) and thus should be contrasted with the approach of Christidis and Stott (2015), who likewise employ approximately 40 -member coupled model simulations but draw from seven different models.

We take a quantitative approach to determine causes and changes in the occurrence of record-setting rains as were observed in May 2015 over the southern Great Plains. Texas and Oklahoma each reported monthly rainfall that far exceeded their prior wettest May, and in fact exceeded the prior wettest month since at least 1895 . These totals were accumulated from a nearly continuous sequence of heavy rain storms that were linked to a persistent atmospheric circulation pattern, a type of teleconnection often experienced during El Niño springs (e.g., Wang et al. 2015). During 2015, a strengthening El Niño event was present and it has been conjectured by Wang et al. that the dynamical effects of the 2015 El Niño were strengthened due to climate change, thereby making the extreme magnitude of the event more probable. Our study tests the hypothesis that human-induced dynamic and thermodynamic drivers increased the likelihood and severity of an extreme May rainfall over Texas/Oklahoma (TX/OK) in 2015. It further tests the hypothesis that El Niño, as a natural mode of variability, was a necessary condition for such rains to occur, and that climate change increased the effectiveness by which El Niño-related teleconnection dynamics influence the region's extreme rainfall probabilities. Our interpretation of necessity is consistent with Hannart et al. (2016), who provided theoretical considerations on necessity, sufficiency, and probabilities of causation for extreme climate events.

It is well known that El Niño-Southern Oscillation (ENSO) affects global weather and climate conditions (e.g., Bjerknes 1969; Horel and Wallace 1981; Webster 1981; Hoskins and Karoly 1981; Hoerling et al. 1997; Trenberth et al. 1998), including the likelihood of extreme rainfall on daily to intraseasonal time scales (e.g., Gershunov 1998; Gershunov and Barnett 1998; Cayan et al. 1999; Haylock et al. 2006; Grimm and Tedeschi 2009). Likewise, emerging research indicates that $\mathrm{El}$ Niño and its teleconnections may change in a warming world (e.g., Timmermann et al. 1999; Meehl and Teng 2007; Latif and Keenlyside 2009; Collins et al. 2010; Cai et al. 2015). Our purpose is to apply robust methods that might better quantify the individual contribution of $\mathrm{El}$ Niño-related dynamics in causing the extreme event, and how the production of that event in association with El Niño has itself changed over time.

A description of the observational datasets used to characterize the May 2015 extreme rains appears in section 2a, while the climate simulations used herein are described in section $2 b$. The statistical-dynamical framework itself is described in section 3. Section 4 presents results of the application of our framework to the May 2015 extreme rainfall. Results of section 4 apply extreme value theory, described in the online supplemental material, to explicitly determine how extreme event statistics were affected by climate change. Section 5 presents a summary of principal findings and a discussion of the broader interpretation of results within a framework of dynamic and thermodynamic drivers.

\section{Datasets}

\section{a. Observational data}

Contiguous U.S. precipitation for 1895-2015 is derived from National Oceanic and Atmospheric Administration (NOAA) U.S. Climate Division data (NCDC 2002). Analyses of TX/OK averaged conditions are constructed by area-weighting the 10 and 9 individual climate divisions available for Texas and Oklahoma, respectively. Monthly precipitation for the domain averages is calculated, and we focus our analysis on May during which the 2015 extreme rainfall occurred. For global analysis of observed precipitation, we utilize the CPC Merged Analysis of Precipitation (CMAP) dataset spanning 1979-2015 (Xie and Arkin 1997).

Global sea surface temperatures (SSTs) from 1895 to 2015 are obtained from the merged Hadley-NOAA/OI sea surface temperature and sea ice concentration dataset (Hurrell et al. 2008). The SST anomalies of May 
2015 are calculated relative to the historical climatology of May SSTs from 1895 to 2014. Geopotential heights at $250 \mathrm{hPa}$ (Z250) for 1948-2015 are based on the NCEPNCAR reanalysis dataset (Kalnay et al. 1996).

A May exceedance of SST anomalies in the Niño-3.4 region $\left(5^{\circ} \mathrm{S}-5^{\circ} \mathrm{N}, 170^{\circ}-120^{\circ} \mathrm{W}\right)$ relative to a $1948-2014$ climatology is calculated, in which SST anomalies more than one standard deviation above the climatology mean are considered El Niño events. Composites of Z250 anomalies relative to a 1948-2014 climatology are made based on the historical May El Niño events and May 2015 El Niño, respectively.

\section{b. Model data}

Climate simulations are based on the 40-member runs of the NCAR Community Earth System Model version 1 (CESM1; Kay et al. 2015). The model is subjected to observed estimates of time varying greenhouse gases, anthropogenic aerosols, and solar and volcanic aerosol variability during 1920-2005 ("all forcing" simulations), and by an RCP8.5 scenario for greenhouse gas emissions and anthropogenic aerosol changes for 2006-2100. The May monthly rainfall, Z250, and SST simulations from 1920 to 2080 are available on a $1.25^{\circ} \times 1^{\circ}$ grid for CESM1. The model data of precipitation are interpolated to U.S. Climate Divisions, and TX/OK May averages are calculated.

Simulated El Niño events during 1920-2015 are identified as in observations except relative to a 1920-2015 climatology for each run of CESM1. We define SST anomalies more than one standard deviation above (below) the climatology mean as El Niño (La Niña), and the rest as neutral cases. Additionally, in order to investigate the climate change effects on El Niño-related extreme rainfall, we also compare statistics across three different periods, 1920-50, 1985-2015, and 2050-80, which are representatives of historical, recent past, and future climate. We selected the 30 -yr period immediately prior to 2015 to assess if there were indicators for a change in the event likelihood since the early twentieth century that might have led one to anticipate the extreme event of May 2015. For each 30-yr period, the SSTs and the Z250 are first detrended, and anomalies are calculated relative to their respective $30-\mathrm{yr}$ climatology for each member of CESM1. In this manner, any SST trend is removed so as to model changes in El Niño frequency that is not conflated with a warming trend. The Niño-3.4 SST standard deviation, used to identity El Niño events, is computed separately for each 30 -yr period with values that vary from $0.62^{\circ}$ to $0.81^{\circ} \mathrm{C}$ among the periods. We have tested the sensitivity of our analysis to alternate El Niño threshold assumptions, for instance using a single standard deviation threshold based on the
1920-2015 model simulation period. While affecting the sample sizes of El Niño events so identified, our subsequent calculations of statistics of El Niño-conditioned extreme rainfall probabilities are robust to either a varying El Niño frequency or a different El Niño magnitude threshold assumption.

Differences in climate statistics among these three periods are principally related to changes in humanrelated emissions of greenhouse gases and anthropogenic aerosols. In subsequent sections, we will refer to these effects as human-induced climate change, or sometimes simply as climate change. The large samples of model data permit statistically robust estimates of differences in the frequency and intensity of TX/OK precipitation extremes in relation to different ENSO phases in each study period, an exercise not possible from observations alone. We apply Bayesian inference for estimating parameters of the generalized Pareto distribution (GPD) to derive return levels of extreme rainfall, the details of which are provided in the online supplemental material.

\section{A statistical-dynamical framework for assessing the individual and mutual effects of climate change and ENSO on extreme events}

A statistical-dynamical framework is used to determine the combined effects of El Niño and anthropogenic climate change on an extreme rainfall event. A variety of approaches are beginning to be utilized in the nascent science of attributing individual weather events to human influence (e.g., Herring et al. 2015; National Academies of Sciences, Engineering, and Medicine 2016). In concept, our study is most similar to those that account for conditions at the place and time of the event's happening (e.g., Perlwitz et al. 2009; Pall et al. 2011; Dole et al. 2011; Hoerling et al. 2013, 2014; Christidis and Stott 2015).

Conceptually, our approach follows Shepherd (2016) by examining the conditionality of extreme monthly rains associated with a variety of factors and physical processes that are believed to be important in understanding the 2015 event's likelihood and severity. Shepherd (2016) illustrates the concept of extreme event probability conditioned on some dynamical process using the following statistical formulation:

$$
P(E)=P(E \mid D) P(D)+P(E \mid \mathrm{ND}) P(\mathrm{ND}),
$$

where $E$ is the extreme event, which can represent the occurrence of the extreme event or the magnitude/severity of the event, $D$ is some dynamical situation, and ND is not that dynamical situation (i.e., the complement 
of $D$ ). Examples of $D$ include a particular atmospheric circulation (see Christidis and Stott 2015) such as blocking (see Dole et al. 2011), or a phase of ENSO as studied herein. Note that $P(D)$ denotes the probability of the dynamical situation and $P(E \mid D)$ denotes the conditional probability of the extreme event in the presence of that dynamical situation, while $P(E \mid \mathrm{ND})$ is also a conditional probability of the event except linked to the absence of that dynamical process whose probability is given by $P(\mathrm{ND})$.

Varying Eq. (1) under the assumption of small differences, Shepherd (2016) expresses long-term changes in event probability (e.g., due to anthropogenic forcing or other factors) as

$$
\begin{aligned}
\delta P(E)= & \delta P(E \mid D) P(D)+P(E \mid D) \delta P(D) \\
& +\delta[P(E \mid \mathrm{ND}) P(\mathrm{ND})] .
\end{aligned}
$$

Under the assumption that $D$ is the predominantly present when an event occurs, Eq. (2) can be simplified as

$$
\delta P(E)=\delta P(E \mid D) P(D)+P(E \mid D) \delta P(D) .
$$

Two factors contribute to changes in event probability [i.e., $\delta P(E)$ ]: changes in probability of the dynamical condition itself [i.e., $\delta P(D)]$ and changes in the underlying physical relationship between the event and attending dynamical condition [i.e., $\delta P(E \mid D)]$.

The generic notation of $P(E \mid D)$ indicates a physical relationship linking the dynamical condition $(D)$ and the extreme event $(E)$. For instance, $f: D \stackrel{a}{\rightarrow} E$, where $D$ and $E$ are connected by the physical relation $a$, which can involve both underlying dynamic and thermodynamic processes. In the context of change as expressed by (3), the change in conditional event probability can be modulated by changes in both underlying dynamic and thermodynamic processes, which are encapsulated by the link indicator $a$. Under a linear approximation, changes in the physics that determine extreme event likelihood are expressed as follows:

$\delta a=a_{1} \times \delta$ dynamic $+a_{2} \times \delta$ thermodynamic $+a_{3}$,

where $a_{1}, a_{2}$, and $a_{3}$ are regression coefficients of the dynamic and thermodynamic processes. Thus, even if the dynamic condition $D$ were unaffected by climate change $[\delta P(D)=0]$, the relationship of $D$ and $E$ (as modulated by $a$ ) can nonetheless be affected via changes in physical processes. The term $\delta P(E \mid D)$ in (3) therefore indicates a change in the extreme event probability resulting from a change in the underlying physical interrelationship. In the context of our particular situation

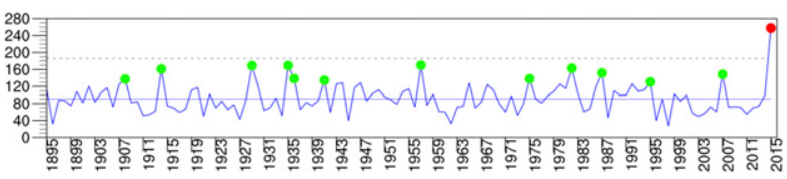

FIG. 1. Observations of May rainfall from 1895 to 2015. The horizontal blue line represents the climatology of 1895-2014. The dashed line represents the three standard deviations of the historical May rainfall from 1895 to 2014. The green dots are the prior 12 events exceeding the $90 \%$ quantile of the historical May rainfall. The red dot is the May 2015 event.

of TX/OK rains, this could involve both dynamic processes via a change in the Rossby wave response to El Niño (e.g., changes in the climatological waveguide that modulate the poleward and eastward dispersion of energy emanating from the El Niño region) and thermodynamic processes (un)related to El Niño dynamics via changes in water vapor and thermal stability (i.e., local factors that modulate the potential for heavy precipitation generation).

We will have occasion to refer to this heuristic framework when interpreting our diagnostic results on the causes for the extreme May 2015 TX/OK rains. In our paper, the extreme event (i.e., $E$ ) of Eqs. (1)-(3) is the May 2015 rainfall averaged over TX/OK or a rainfall magnitude comparable to that event, while the concurrent 2015 El Niño is a conditioning dynamical component (i.e., $D$ ). We will subsequently show that an event having the intensity of the May 2015 rains was extremely unlikely without El Niño as a dynamical conditioning factor, justifying a focus on Eq. (3) as an analytical framework.

\section{Results}

\section{a. Comparing observed and modeled May precipitation for $\mathrm{TX} / \mathrm{OK}$}

Figure 1 presents the 1895-2015 time series of observed May rainfall averaged for TX/OK. The 2015 monthly rainfall total of $258 \mathrm{~mm}$ was about $50 \%$ greater than the prior record of $170 \mathrm{~mm}$, which also occurred during an El Niño in May 1957. TX/OK May rainfall exhibited a slight, but statistically insignificant, negative trend over the period 1895-2014 that preceded the occurrence of the extreme 2015 rainfall event.

We define a threshold for extreme rainfall as May totals exceeding a 90th quantile of the 121 historically observed TX/OK May monthly rainfall totals. This threshold is about $130 \mathrm{~mm}$. The May 2015 event (red dot) was the most severe of all prior exceedances (12 green dots), having a total rainfall that was double the 90th quantile threshold. The purpose of defining such a 
(a)

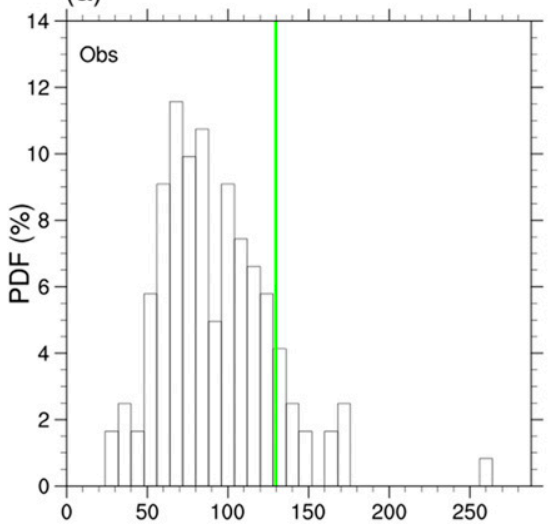

(b)

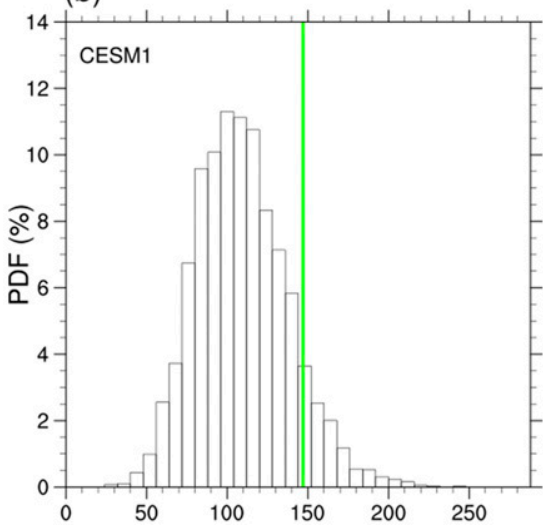

FIG. 2. Histogram plots of probability density functions (PDFs) for (a) the observed May precipitation from 1895 to 2015 and (b) the CESM1 simulations of May rainfall from 1920 to 2015. The vertical green lines represent the threshold of the $90 \%$ quantile based on the historical observations from 1895 to 2014 and the CESM1 simulations from 1920 to 2015, respectively.

threshold is to derive meaningful statistics of the tail distribution constructed with threshold exceedances so as to interpret the severity and likelihood of one particular extreme case: the 2015 event [i.e., $E$ of Eqs. (1)-(3)].

Figure 2 compares histograms of TX/OK May rainfall based on the historical observations (Fig. 2a) and the historical CESM1 simulations (Fig. 2b). The two distributions are quite similar, although with a wet bias in the model. Threshold values for extremes will be based on each dataset's 90th quantile statistic, which corresponds to $130 \mathrm{~mm}$ in observations and $144 \mathrm{~mm}$ in CESM1 (green lines). The CESM1 large ensemble yields 345 extreme May rainfall events exceeding a 90th quantile during 1920 to 2015.

We next compare observed and model statistics for peaks beyond their respective exceedance thresholds using the Bayesian-GPD approach. Figure 3 shows the box-and-whisker plots of posterior distributions of the (left) scale and (right) shape parameters of the GPDs for observations (black) and CESM1 (gray), separately. To facilitate meaningful comparisons, the model analysis is based on sample sizes similar to the observed sample size by applying the GPD analysis to each run of CESM1 separately. The box-and-whisker plots show the aggregate results of all 40 runs; for instance, the median value plotted in Fig. 3 can be interpreted as the average value of the medians of each run's distribution. The CESM1based GPD parameters indicate lower variance (smallerscale parameter) but a heavier tail (larger positive shape parameter) of extreme values compared to observations. These biases operate in opposite directions in terms of affecting extreme event statistics; for example, the model's heavier tail enhances extreme value probabilities. Results using various exceedance thresholds (e.g., 75th, 80th, and 85th quantiles) are not significantly different from using a 90th quantile.

\section{b. Unconditional probabilities of the May 2015 TX/ OK rains}

We first estimate the unconditional probability of the May 2015 TX/OK rains [i.e., $P(E)]$. Figure 4 summarizes the return period (abscissa) and the return level (ordinate) of historical extreme May rainfall averaged across the domain of TX/OK. Historical observations for 1895-2014 reveal that the magnitude of 2015 extreme rain event (solid circles) was considerably more intense than the prior record (open circles), with the prior highest May rainfall total likely being a "weak record" in so far as its estimated return period is approximately 50 to 100 years. By contrast, the extreme value of the 2015 event falls into the $90 \%$ uncertainty of our estimates for a 400-yr return level. This is the case even when the 2015 event is included in the assessment (not shown). The results indicate that the TX/OK May 2015 flood was highly unusual from a historical perspective.

Repeating the analysis by leveraging the large samples available from the climate model largely supports the observational inference of the extreme character of the May 2015 rains. Each single run of CESM1 simulations for 1920 to 2015 is diagnosed in the manner analogous to observations, and Fig. 4 shows the box-and-whisker plots of the aggregate results of all 40 runs. The model-based analysis reveals the observed 2015 extreme event was also close to a 400-yr (or longer period) event (also see Fig. A1, which utilizes the tail of CESM1 simulations to 

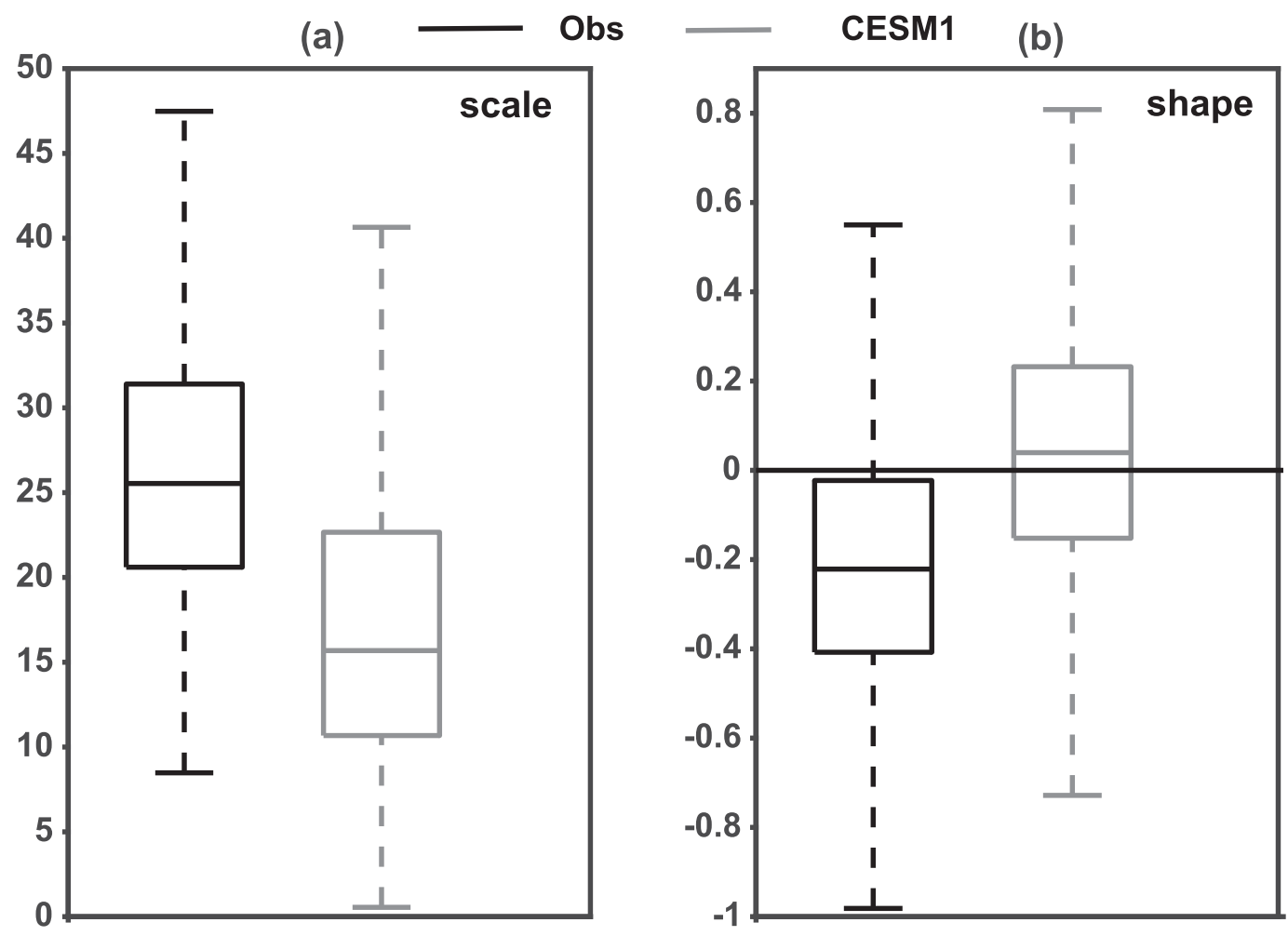

FIG. 3. Posterior distributions of distribution parameters of (a) scale and (b) shape for observations (black) and 40 runs of CESM1 (gray), separately.

produce return level analysis for a continuous spectrum of return periods to $1000 \mathrm{yr}$ ). This result, along with Fig. 3, leads us to view CESM1 as a reasonably suitable tool for assessing return level and return period of extreme monthly rainfall occurrences such as the May 2015 event.

\section{c. Conditional probabilities of extreme TX/OK rains associated with ENSO states}

Given that a strong El Niño event occurred in 2015 (Fig. 5a), we examine how TX/OK extreme May rainfall probabilities are conditioned by SST variability in the tropical east Pacific. First we note that, antecedent to the 2015 event, both historical observations (Fig. 5b) and model simulations (Fig. 5c) reveal the wettest Mays over $\mathrm{TX} / \mathrm{OK}$ to preferentially occur in concert with warmer than normal central and eastern equatorial Pacific SSTs. The results thus support an argument, first proposed by Wang et al. (2015), that the extreme 2015 TX/OK rains may have had a dynamical cause tied to El Niño. The agreement in SST patterns between observations and model is remarkably high in the Indo-Pacific basin, attesting to the realism of the model's SST response to El Niño, and we will subsequently examine the dynamical processes associated with tropical-extratropical interaction linking TX/OK May rains to tropical Pacific
SST variability (section 4e). We note here that CESM1 realistically simulates key features of the local and remote atmospheric responses associated with El Niño during May (see appendix B), and that the El Niño wet signal over TX/OK in the historical composite is realistically simulated as part of CESM1's teleconnection processes (not shown).

We diagnose the individual effects of El Niño and La Niña/ENSO-neutral tropical Pacific states on extreme TX/OK rains, thereby providing estimates for $P(E \mid D)$ and $P(E \mid \mathrm{ND})$ in Eq. (1), respectively. The results in Fig. 6 are based only on the large-ensemble CESM1 simulations, recognizing that a similar analysis using observations is not feasible owing to the small sample size. The extreme event statistics of Fig. 6 are derived from exceedances above the $90 \%$ quantile for May rainfall that were further conditioned on ENSO phase, resulting in 64 and 62 samples for El Niño and La Niña, respectively. Figure 6 shows TX/OK May extreme rainfall statistics corresponding to El Niño (green), La Niña (purple), and ENSO-neutral (yellow) conditions. A strong conditioning of heavy rainfall statistics to ENSO phase is revealed. For all return periods, the median precipitation amount associated with extreme events is about $30 \%$ greater during El Niño than during La Niña. An event magnitude that would occur every 


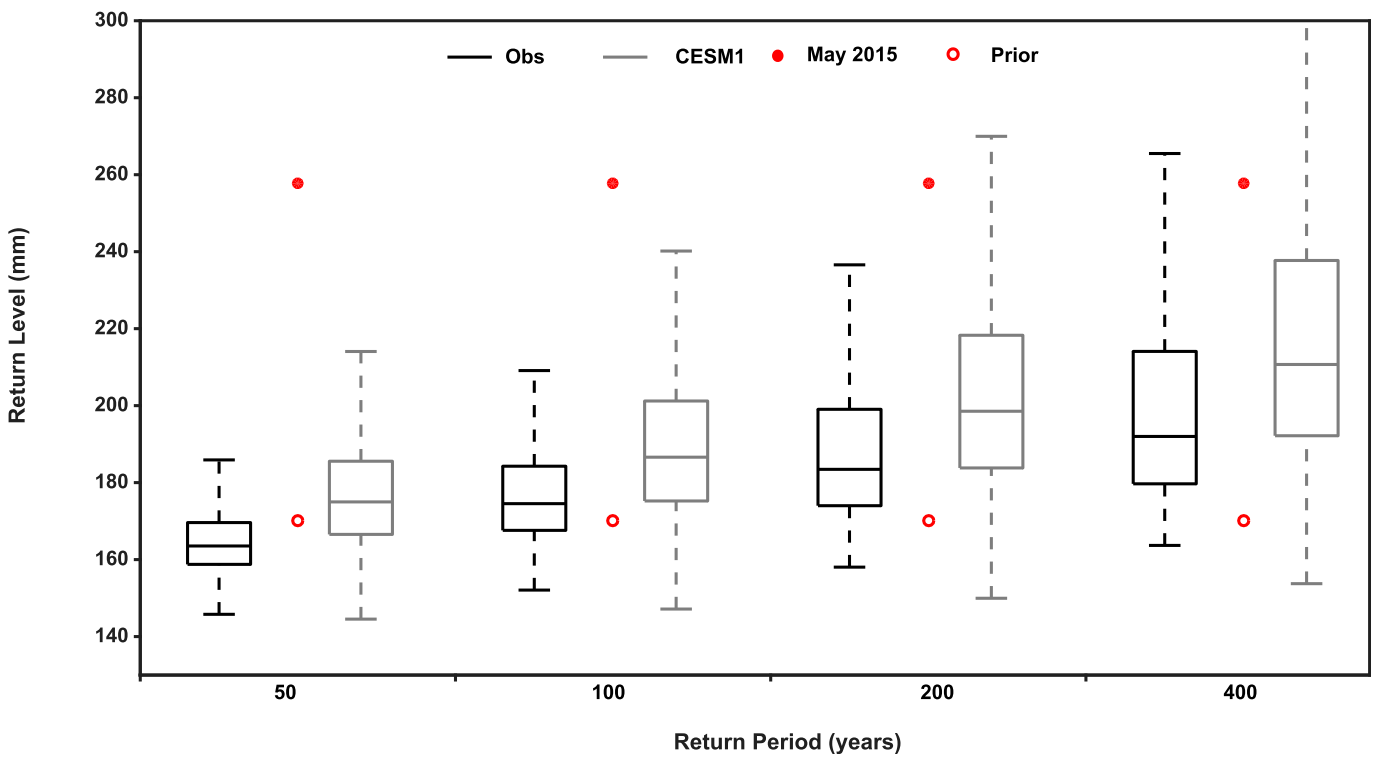

FIG. 4. Return level (mm) and return period (yr) estimations for observations (black) and CESM1 simulations (gray), respectively. The results are based on the exceedances above $90 \%$ quantile of May rainfall using observations prior to May 2015 and 40 runs of CESM1 simulations from 1920 to 2015. Box plots of distributions of return levels show the median (center mark) and the 25th (lower edge) and 75th (upper edge) percentiles, and the whiskers quantify the $95 \%$ credible interval. Red dots are the observed TX/OK May 2015 rainfall and red circles are the prior event.

50 El Niño years $(\sim 190 \mathrm{~mm})$ occurs at most about every 400 La Niña years considering a $90 \%$ uncertainty range.

Of particular importance, the results of Fig. 6 indicate that El Niño was virtually a necessary condition for the occurrence of an extreme rainfall event over TX/OK having the observed magnitude in 2015. The occurrence of an event having a magnitude as large as was observed in 2015 (closed circle) can only be reconciled with the presence of the dynamical forcing associated with $\mathrm{El}$ Niño. Our finding is also supported by the alternative examination in which the El Niño-related return level is shown as a continuous function of the extended return period (see Fig. A2). CESM1 simulations indicate that the event (i.e., a May rainfall equal to or exceeding $258 \mathrm{~mm}$ ) was exceedingly unlikely to occur in the absence of El Niño (i.e., either ENSO-neutral or La Niña ocean states).

El Niño alone was certainly not the sole factor responsible for the totality of the rains that fell over TX/ OK in May 2015, despite being critical for achieving its record setting extreme peak value. Other factors may also have conditioned the likelihood for such an event. In particular, the results of Fig. 6 do not address how human-induced climate change may also have played a role in so far as that analysis aggregated all statistics of extreme May rainfall during 1920-2015 in the CESM1 simulations. We thus turn next to the question how the further conditionality associated with climate change, in tandem with El Niño, affected the odds of the May 2015 event.

\section{d. Mutual effects of anthropogenic contributions and El Niño on extreme TX/OK rains}

We diagnose statistics of May TX/OK El Niño-related extreme rainfall events for three nonoverlapping periods $(1920-50,1985-2015,2050-80)$ in order to identify the role of human-induced climate change in the presence of El Niño interannual forcing. This diagnosis is akin to a calculation of the second term in Eq. (3) [i.e., $\delta P(E \mid D)]$. As a context for changes in extremes, Fig. 7 presents analysis of the simulated changes in mean climate (2050-80 minus 1920-50) for (top) surface temperature, (middle) precipitation, and (bottom) column precipitable water. These mean changes are broadly consistent with CMIP5 climate model simulations overall (e.g., IPCC 2013) in revealing a warmer world, having increased atmospheric water vapor. The simulated May climate over TX/OK is $3.6^{\circ} \mathrm{C}$ warmer, receives $6 \%$ more rainfall, and has $23 \%$ greater column precipitable water during 2050-80 compared to $1920-50$.

Figure 8 presents extreme May rainfall event statistics associated with El Niño during the early twentieth century (blue), the recent past (red), and the late twentyfirst century (magenta). The results indicate no significant difference in the likelihood of extreme May rainfall 
(a)

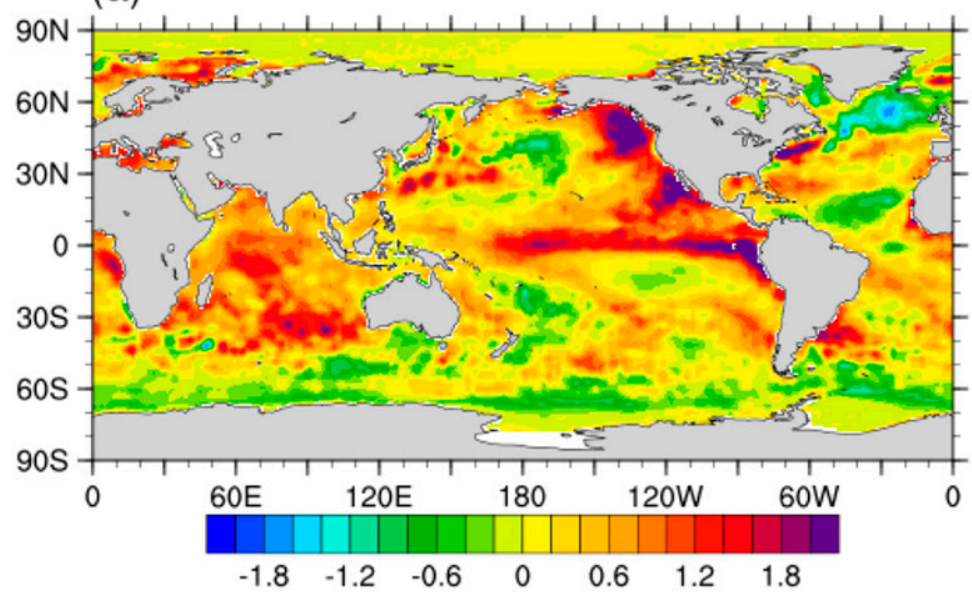

(b)

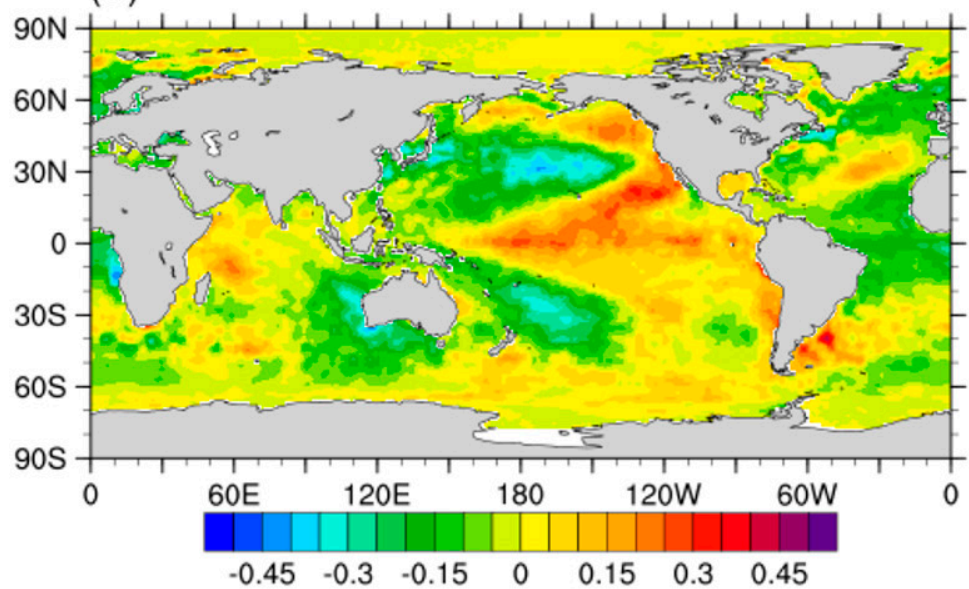

(c)

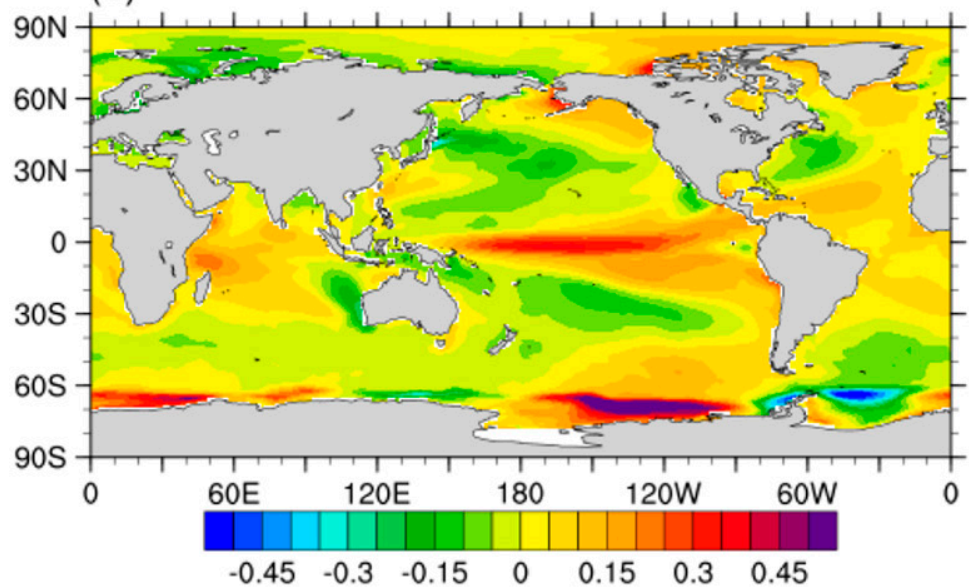

FIG. 5. Observed and CESM1 simulated SST anomalies $\left({ }^{\circ} \mathrm{C}\right)$. The observed May 2015 anomalies are calculated relative to (a) the 1895-2014 climatology and (b) the averaged observations of May SST anomalies corresponding to the wettest May precipitation quintile from 1895 to 2014. (c) CESM1 ensemble mean of May SST anomalies corresponding to the wettest May precipitation quintile from 1920-2014. 


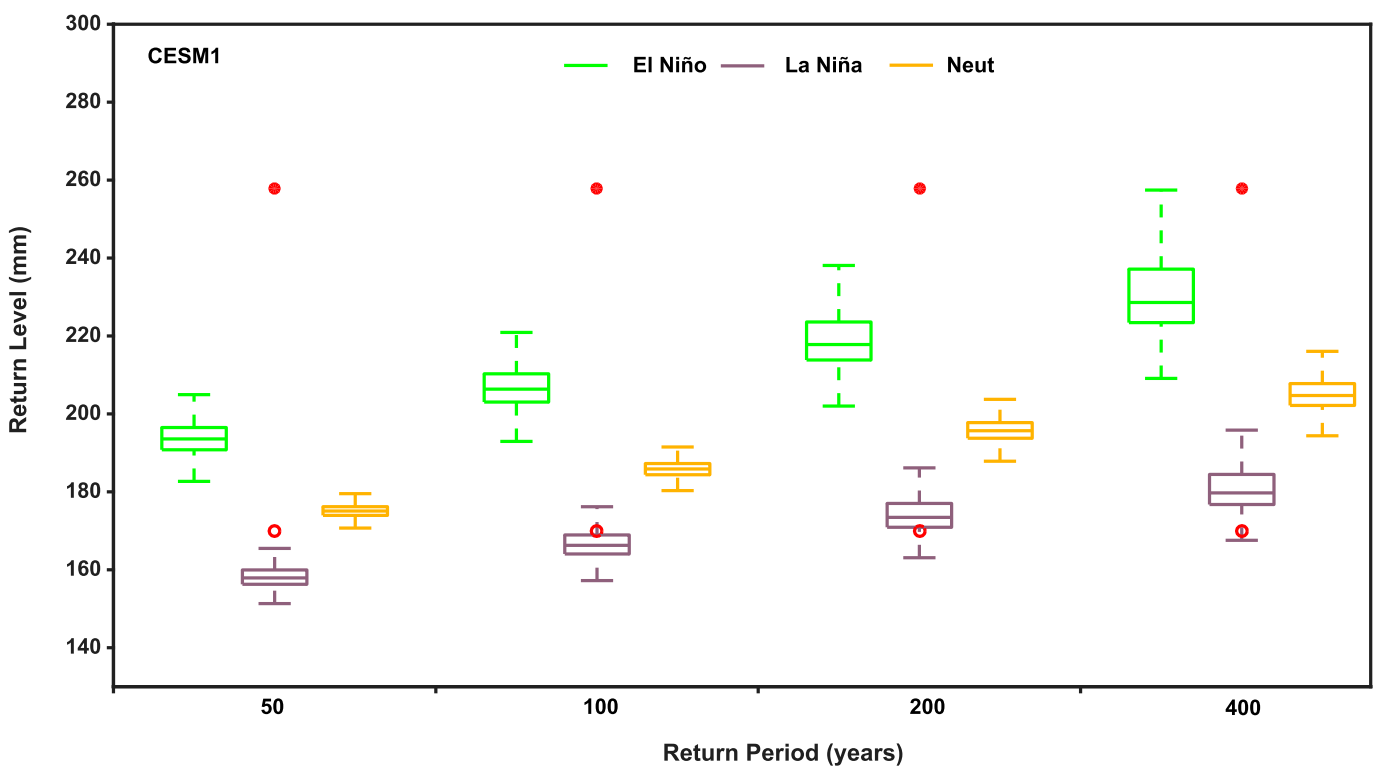

FIG. 6. Return level (mm) and return period (yr) estimations based on the exceedances above the $90 \%$ quantile of May rainfall associated with El Niño (green), La Niña (purple), and neutral (yellow) using CESM1 simulations. Box plots of distributions of return levels show the median (center mark) and the 25th (lower edge) and 75th (upper edge) percentiles, and the whiskers quantify the $95 \%$ credible interval. Red dots are the observed TX/OK May 2015 rainfall and red circles are the prior event.

under recent-past climate conditions compared to the early twentieth century-the box-and-whisker plots reveal the interquartile range to be statistically indistinguishable across all severities ranging from 50- to 400-yr return periods (also see Fig. A3). A similar result occurs based on diagnosis of the unconditional probability of extreme May rainfall (see Fig. A4), indicating that, regardless of ENSO phase, no significant change in TX/OK extreme rainfall likelihoods has occurred during 1985-2015 relative to 1920-50. Of particular relevance toward explaining causes of an event having the magnitude of the 2015 May rains, comparison of the conditional (Fig. 8) and unconditional (Fig. A4) probabilities reveals that the dynamical effect of El Niño was a requisite condition for the occurrence of such an extreme, whereas climate change was not.

Turning to projections for the latter half of the twentyfirst century (magenta box plots), a modest but statistically significant increase in extreme May precipitation during El Niño events occurs relative to the early twentyfirst century, affirmed by the two-sample KolmogorovSmirnov (KS) test at the $95 \%$ significance level. Estimated return levels are about $5 \%$ greater (wetter) than for their current climate counterparts. Furthermore, a nearly identical 5\% increase in return levels for unconditional and El Niño-conditioned samples (cf. Figs. 8 and A4) implies that the third term of Eq. (3) is negligible. The impact of changes in the El Niño dynamical condition [i.e., $\delta P(D)$ ] is thereby judged to be secondary to changes in the physical linkage of El Niño to TX/OK extreme rains [i.e., $\delta P(E \mid D)]$.

We will show in the next section that this projected $5 \%$ increase in extreme May rainfall threshold exceedances is not symptomatic of a change in El Niño-related dynamics (e.g., atmospheric teleconnection pattern linking El Niño SST forcing with TX/OK May rainfall), but appears to be mainly a consequence of thermodynamic changes. These increases in extreme event magnitude are quite similar to the mean May rainfall increase, but are appreciably less than the $23 \%$ increase in TX/OK atmospheric precipitable water. Indicated here is that the projected change in extreme event magnitude is much less than predicted by a Clausius-Clapeyron relation. Possible reasons for that difference will also be subsequently provided, but suffice it to state here that a similar result is found when repeating the analysis of Fig. 8 but for daily rainfall over the region rather than for monthly averages (not shown).

\section{e. Changes in physical linkages between El Niño and TX/OK extreme May rainfall}

The absence of change in extreme May rainfall associated with $\mathrm{El}$ Niño events in the recent past compared to the early twentieth-century climate [i.e., $\delta P(E \mid D) \approx 0$ ] does not necessarily indicate that underlying physical processes linking El Niño and TX/OK extreme May 
(a)

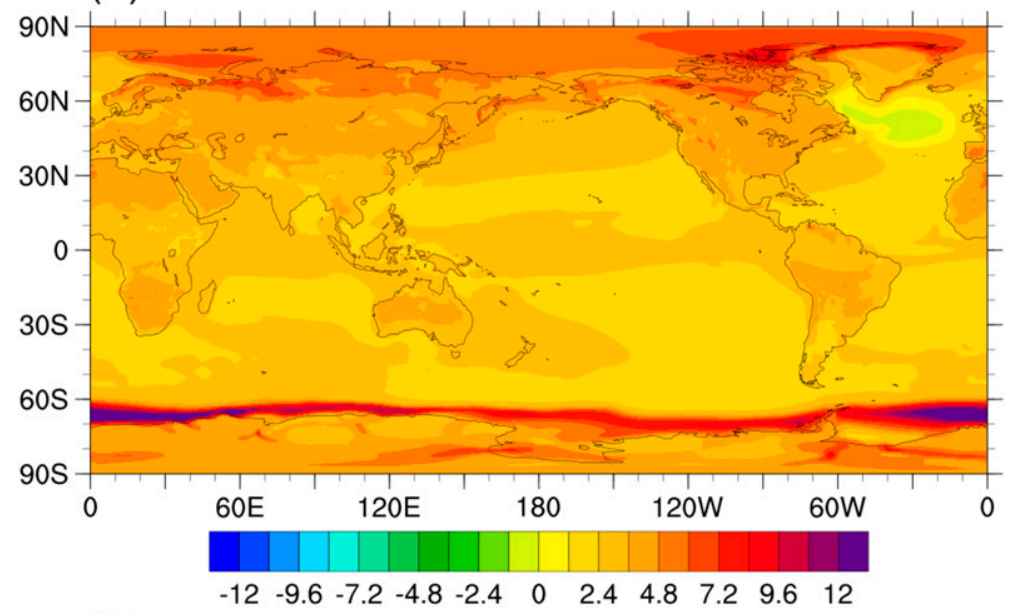

(b)

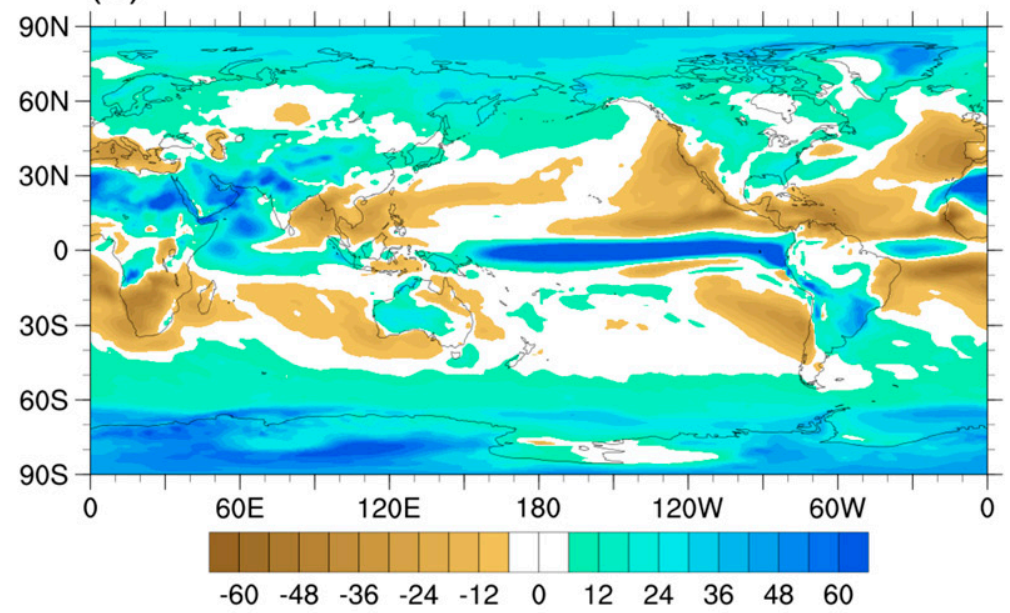

(c)

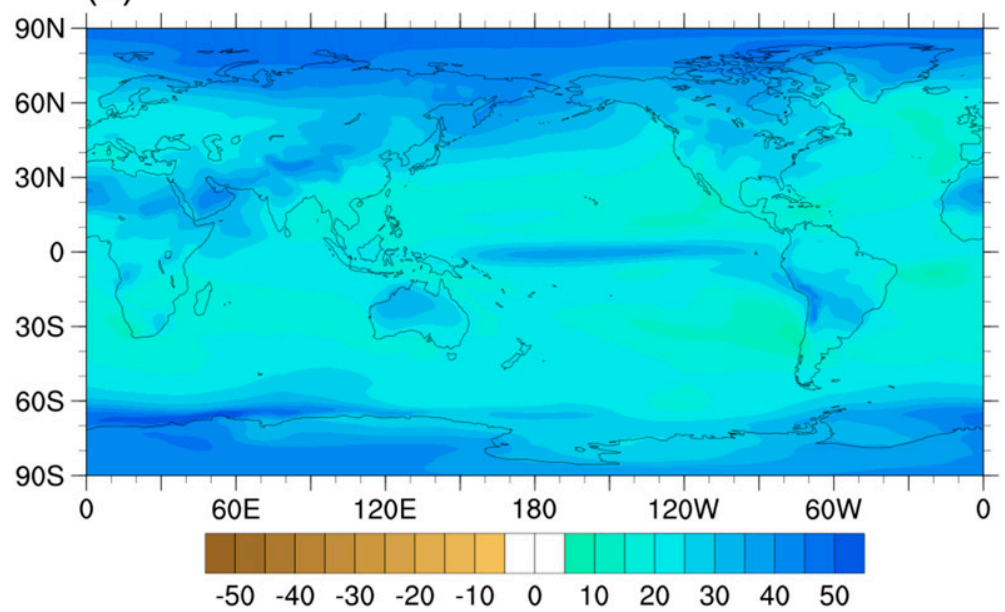

FIG. 7. Averaged composites of CESM1 data for 2050-80 Mays minus 1920-50 Mays for (a) reference height temperature $\left({ }^{\circ} \mathrm{C}\right)$, (b) precipitation in percent $(\%)$, and (c) precipitable water in percent $(\%)$. 


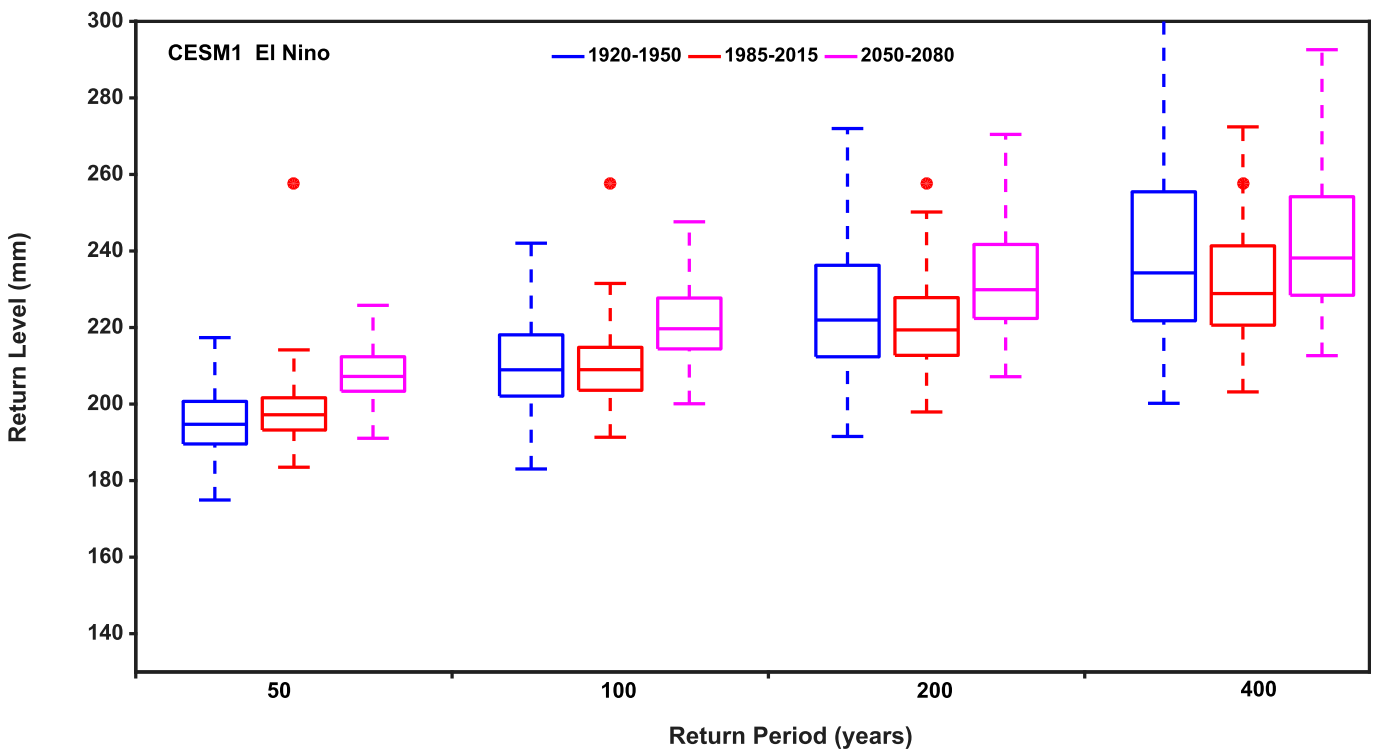

FIG. 8. Return level ( $\mathrm{mm}$ ) and return period (yr) estimations based on the exceedances above the $90 \%$ quantile of El Niño-related May rainfall during 1920-50 (blue), 1985-2015 (red), and 2050-80 (magenta) using CESM1 simulations. Box plots of distributions of return levels show the median (center mark) and the 25th (lower edge) and 75th (upper edge) percentiles, and the whiskers quantify the $95 \%$ credible interval. Red dots are the observed TX/ OK May 2015 rainfall.

rainfall have not changed [i.e., $\delta a \approx 0$ in Eq. (4)]. Here we assess how El Niño-related SSTs and various aspects of its associated atmospheric teleconnection linking El Niño to TX/OK May rainfall have varied through time based on the large-ensemble CESM1 simulations. The results reveal no material changes in the overall atmospheric dynamics during extreme May rainfall events over TX/OK, including the El Niño-related teleconnection.

To illustrate, the left panels of Fig. 9 present observed composites of tropical Pacific SST and rainfall anomalies, and Pacific-North American Z250 anomalies for historical May El Niño conditions, key features that define El Niño and its related dynamics. These are compared to the anomalies observed during the May 2015 extreme event, whose similarity reaffirms that El Niño constitutes an important conditioning factor for extreme rains over TX/OK. Appendix B (see Figs. B1-B3) presents analogous diagnostics based on May El Niño composites derived from the CESM1 large ensemble experiments, shown for each of the three time-slice windows. The simulated El Niño and its related dynamics (left side panels) are in good qualitative agreement with the observed El Niño composites including a composite El Niño wet signal over TX/OK (not shown). Additionally, model composites based on occurrences of extreme TX/OK May rainfall in tandem with El Niño conditions (right side panels) reveal many 250-hPa height features analogous to those observed in 2015. Also note the similarity in tropical Pacific SST anomaly composites among the three periods, especially between the early twentieth century (Fig. B1b) and the late twenty-first century (Fig. B1f). Suggested hereby is a negligible long-term change in the CESM1's simulated dynamical condition $(D)$ accompanying extreme May rainfall over TX/OK, again supporting our earlier interpretation that the second right-side term of Eq. (3) is small.

We next sample three geographical regions (see caption of Fig. 10), spanning the El Niño teleconnection chain that links El Niño physically to TX/OK rainfall, and present diagnoses of the respective variables in Fig. 9 for each of the 30 -yr periods. Shown in the lower panels of Fig. 10 are the statistics for these variables (Niño-3.4 SST, Niño-3.4 rainfall, and western North America 250-hPa heights) based on CESM1 simulated El Niño events. These are created for each of the three time slices, with all anomalies calculated relative the respective period's 30-yr climatology. The mean Niño3.4 SST anomaly during El Niño is $\sim 1^{\circ} \mathrm{C}$, though with some differences in the means among the three time slices (Fig. 10d), being greatest during the early twentyfirst century and weakest during the early twentieth century. This is consistent with the fact that CESM1's Niño-3.4 SST variability is highest overall during the early twenty-first century as previously indicated in 
(a)

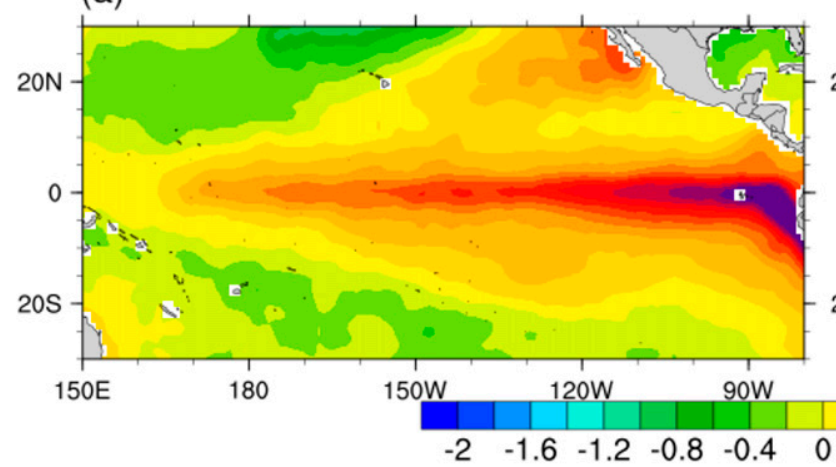

(c)

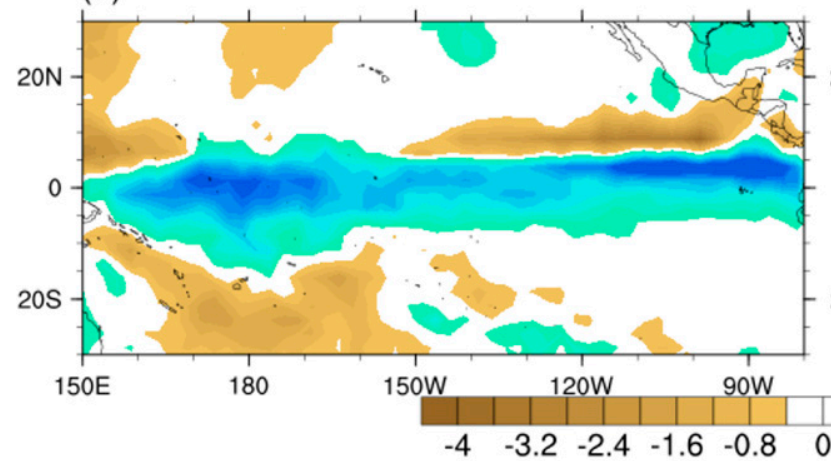

(e)

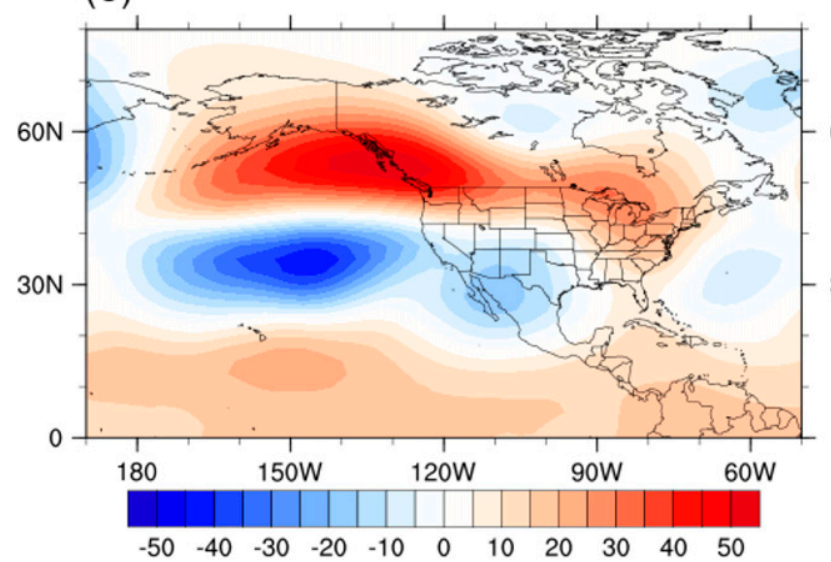

(b)

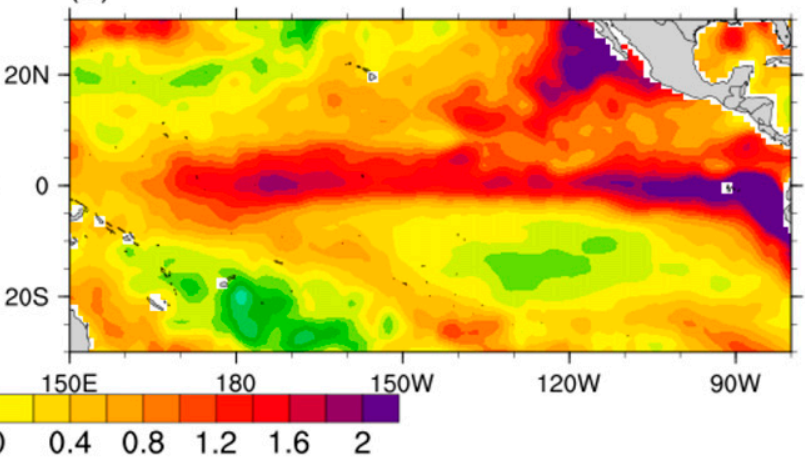

(d)

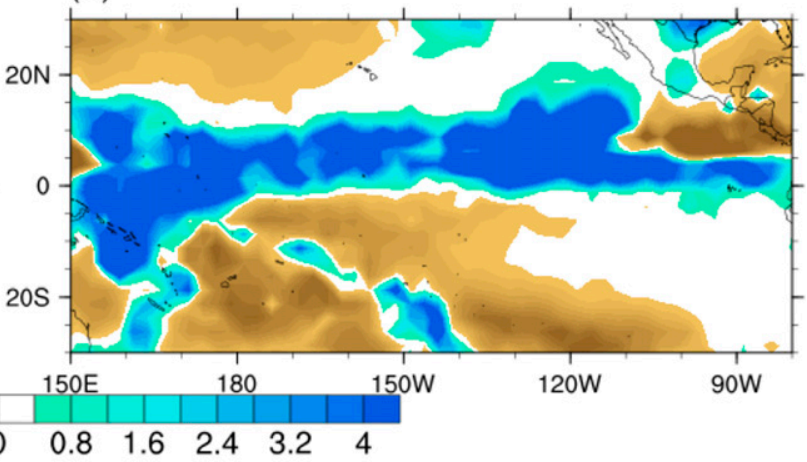

(f)

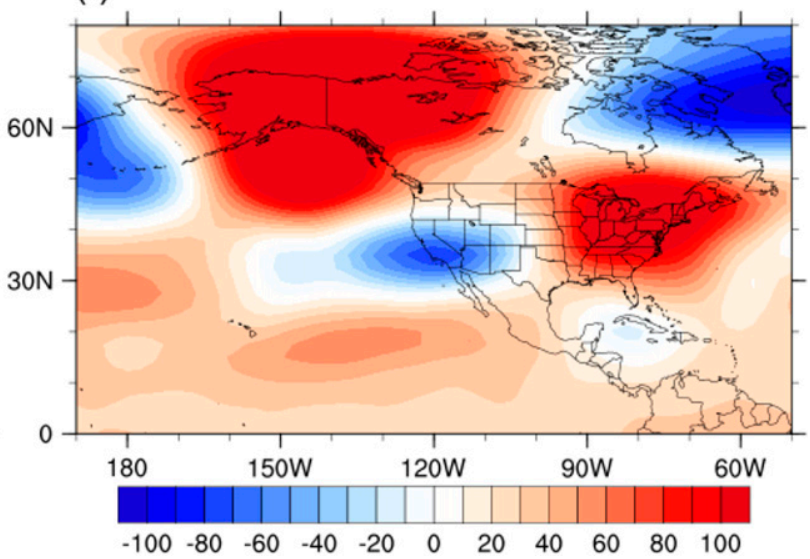

FIG. 9. (top) Averaged composites of observed Hurrell SST anomalies $\left({ }^{\circ} \mathrm{C}\right.$ ) based on (a) May El Niño events and (b) May 2015 relative to the May climatology of 1948-2014, respectively. (middle) Averaged composites of observed CMAP precipitation anomalies (mm day ${ }^{-1}$ ) based on (c) May El Niño events and (d) May 2015 relative to the May climatology of 1979-2014, respectively. (bottom) Averaged composites of observed geopotential height anomalies (m) at $250 \mathrm{hPa}(\mathrm{Z} 250)$ based on (e) May El Niño events and (f) May 2015 relative to the May climatology of 1948-2014, respectively.

section $2 \mathrm{~b}$, reasons for which are beyond the scope of this paper to pursue. Suffice it to note that there is also a commensurately stronger equatorial Pacific enhanced rainfall during those slightly stronger El Niño events of the recent past (Fig. 10e). Importantly, however, as concerns the immediate impact on TX/OK, there is no significant difference (also affirmed by the KS test) in the intensity of the mean 250-hPa low pressure anomaly positioned immediately west of TX/OK that forms part of the upper-air teleconnection chain (Fig. 10f). The upper tropospheric responses to El Niño across the entire Pacific-North American sector are broadly similar for the three time-slice composites (see Fig. B3).

A further indication that overall atmospheric dynamics have not materially changed during occurrences of extreme May rainfall events is provided by analysis of 
(a)

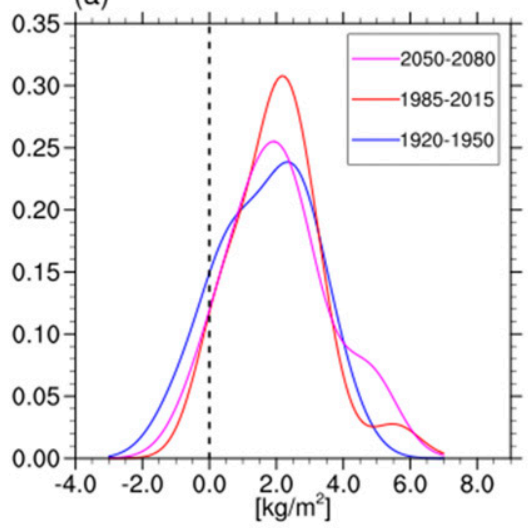

(d)

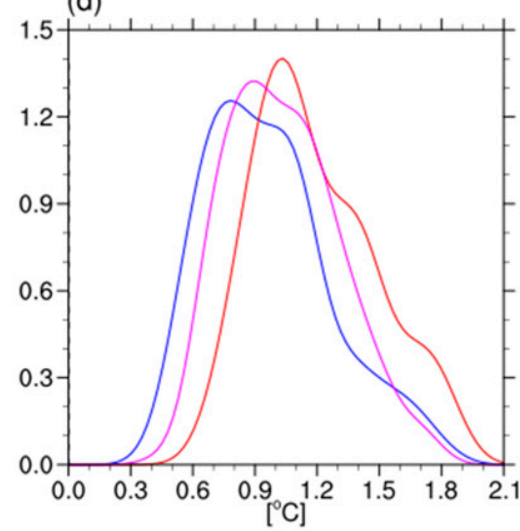

(b)

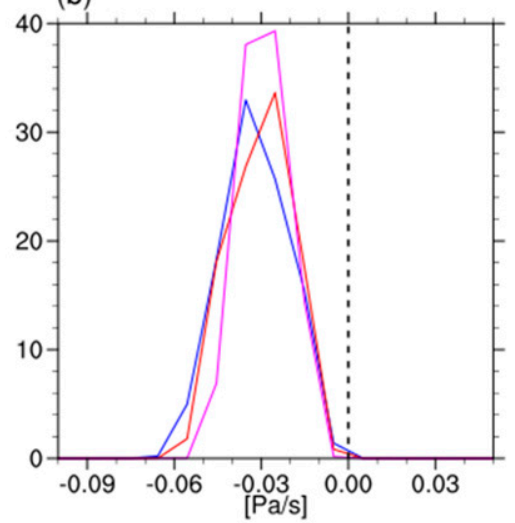

(e)

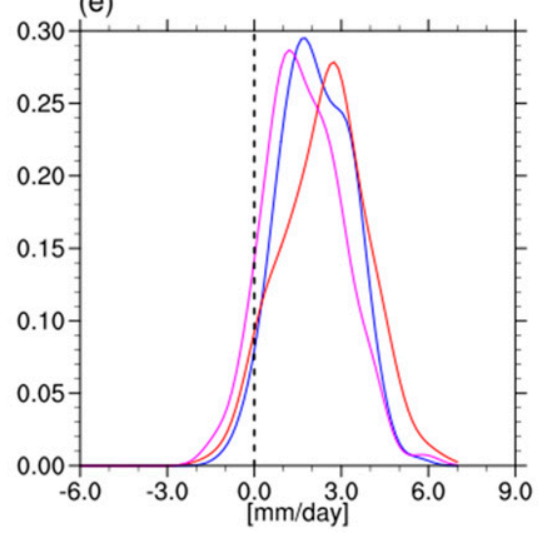

(c)

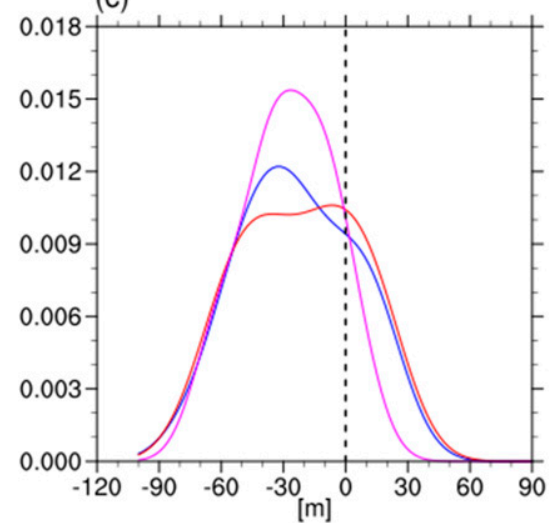

(f)

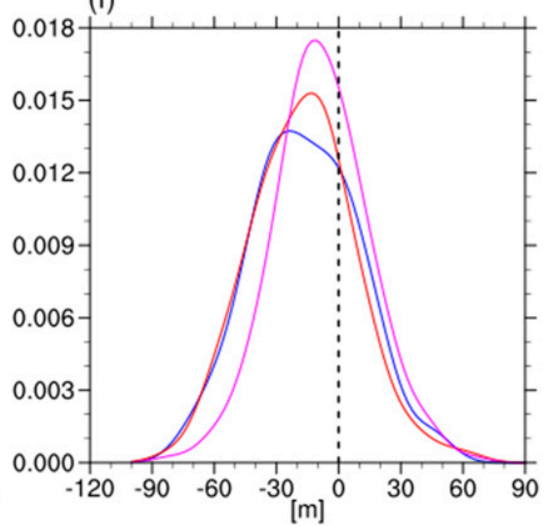

FIG. 10. PDF plots of TX/OK region May El Niño events from CESM1 data for three periods 1920-50 (blue lines), 1985-2015 (red lines), and 2050-80 (magenta lines). The top row includes only wettest May El Niño events for (a) precipitable water averaged over the region $28^{\circ}-37^{\circ} \mathrm{N}, 104^{\circ}-94^{\circ} \mathrm{W}$, (b) vertical velocity averaged over the region $28^{\circ}-37^{\circ} \mathrm{N}, 104^{\circ}-94^{\circ} \mathrm{W}$, and (c) 250 -hPa height averaged over the region: $25^{\circ}-40^{\circ} \mathrm{N}, 115^{\circ}-100^{\circ} \mathrm{W}$ (c). The bottom row includes all May El Niño events for (d) surface temperature, (e) precipitation, and (f) $250-\mathrm{hPa}$ height all averaged over the region $5^{\circ} \mathrm{S}-5^{\circ} \mathrm{N}, 170^{\circ}-120^{\circ} \mathrm{W}$.

midtropospheric vertical motion averaged over TX/OK. The top panels of Fig. 10 summarize statistics of all extreme May TX/OK rainfall events which were used to perform the Bayesian-GPD analysis of sections $4 \mathrm{~b}, 4 \mathrm{c}$, and $4 \mathrm{~d}$. There are approximately 20 samples comprising each distribution for each of the three time slices. The anomalous vertical motion (Fig. 10b) is consistently upward during extreme rainfall events in each sampled $30-\mathrm{yr}$ period (negative 500-hPa $\omega$ anomalies), and the three histograms are statistically indistinguishable. It is interesting to note that a variety of monthly-mean atmospheric circulation patterns yield such upward vertical motion supporting heavy May rainfall. This is suggested by the wide spread in the PDFs of 250-mb height anomalies (Fig. 10c), for which one finds a few samples having monthly mean positive heights over the area immediately west of the TX/OK region. Note also that the mean value of the height anomalies associated with CESM1 extreme rainfall events $(\sim-30 \mathrm{~m})$ is roughly double the magnitude of the El Niño-related mean height anomalies (see Fig. 10f), indicating that El Niño is not the only dynamical process capable of producing extreme May rains over TX/OK.

Concerning thermodynamic indictors accompanying extreme May rains, Fig. 10a shows the column precipitable water averaged over TX/OK-the mean anomaly is positive and of comparable magnitude $\left(\sim+2.5 \mathrm{~kg} \mathrm{~m}^{-2}\right)$ for each period. It is perhaps surprising that some of the extreme May rainfall events actually have below average May precipitable water associated with them. Indeed, we find only a weak correlation between water vapor content and the intensity of extreme May rains among the samples comprising these PDFs (Fig. 11). Such a weak constraint may be one reason why a simple Clausius-Clapeyron thermodynamic perspective alone could overestimate the expected response of extreme rains to climate change in the situation under study herein. Other thermodynamic changes also occur, 

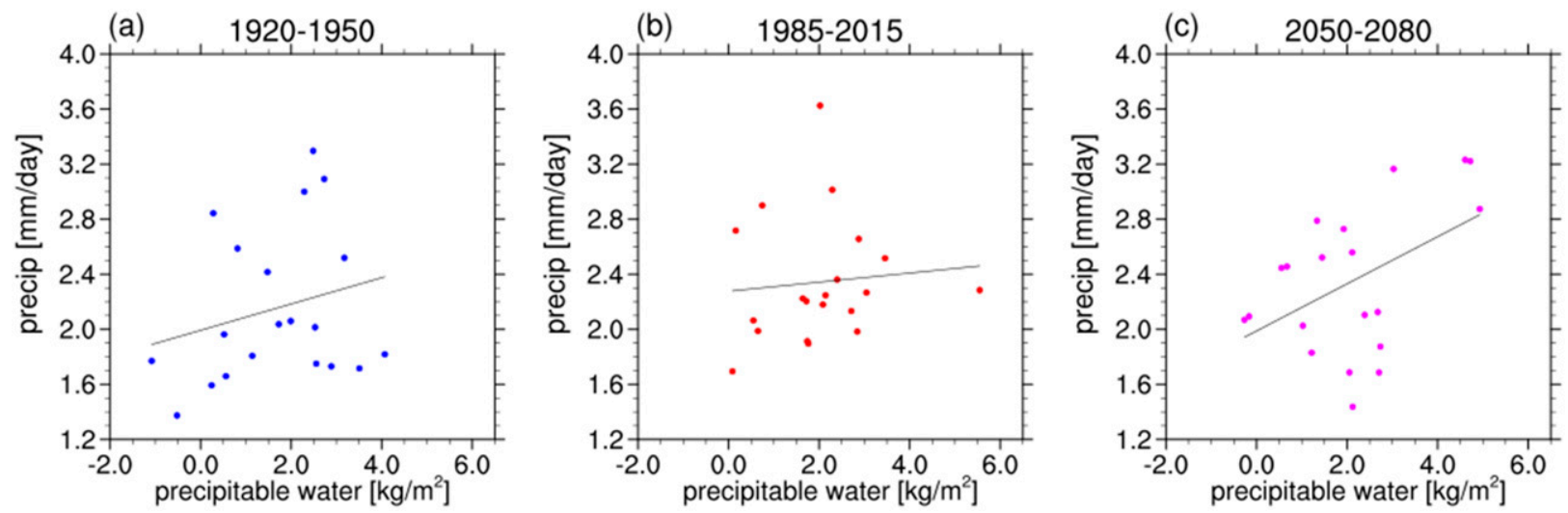

FIG. 11. Scatterplots of TX/OK region wettest May El Niño events from CESM1 precipitable water vs precipitation for three periods 1920-50, 1985-2015, and 2050-80, respectively.

as discussed in section 5, and these may require consideration when drawing inferences about thermodynamic driving of extreme rainfall.

In summary, the overall atmospheric dynamics accompanying extreme TX/OK May rainfall appear to have not materially changed. Our interpretation of the various analyses is that the roughly $5 \%$ increase in return levels for extreme May rains results principally from thermodynamic changes, although these are less in magnitude than expected by a Clausius-Clapeyron relationship.

\section{Summary and discussion}

\section{a. Summary}

Among their recommendations to improve robustness in event attribution, the National Academies of Sciences, Engineering, and Medicine (2016) highlighted a need to better understand effects of both dynamics and thermodynamics in the development of extreme events, and to improve diagnosis of the interplay between natural variability and climate change. The current study has addressed both of these recommendations. It examined how El Niño-related dynamics may have changed in a warming world in a manner that could have altered the intensity and likelihood of an extreme rainfall event. It also presented a formalism for assessing the role of dynamic and thermodynamic factors, and how they interacted to affect an extreme event.

We posed the hypothesis that human-induced dynamic and thermodynamic drivers increased the likelihood and severity of an extreme May rainfall event over Texas/Oklahoma in 2015. We tested the hypothesis that El Niño, a natural mode of variability, was a necessary condition for such rains to occur, and that climate change altered the effectiveness by which El Niño-related teleconnection dynamics drive the region's extreme rainfall probabilities. Furthermore, we tested whether a simple thermodynamic consideration (e.g., a ClausiusClapeyron relation) is sufficient for explaining the occurrence of the 2015 rainfall by examining its strength and effectiveness in constraining the magnitude of such extreme events.

The unusually strong 2015-16 El Niño was comingled with the warmest global mean temperatures since the late nineteenth century, providing an excellent laboratory in which to apply a framework for event attribution. The case challenged our ability to disentangle various factors in a quantifiable manner, and with estimated uncertainty. Our diagnosis first demonstrated within both model and observational data of the last century that the prior TX/OK May rainfall record (which occurred in 1957) was likely a weak record, being a 50100 -yr event. Its recent exceedance was therefore not surprising. However, we found that the magnitude of 2015 rains constituted a very rare occurrence (400-yr or longer return period), which could not have been readily foreseen from perspective of the prior century-long historical record. The reasonable question thus arose, which the paper's hypothesis articulates, of whether the likelihood of such an event has materially changed during the course of the last century. To the extent that climate change was a factor, then perhaps what appeared like a "climate surprise" in May 2015 over TX/ OK was in fact made more probable in recent years than the longer history forewarned.

El Niño alone was found to be a critical condition for such an extreme event to occur in 2015. Analysis of a large (40 member) ensemble of CESM1 simulations for 1920-2015 indicated an extreme rainfall magnitude as large as observed in 2015 to be irreconcilable with either La Niña or ENSO-neutral states of the tropical Pacific. 


\section{(a) $850 \mathrm{mb}$}

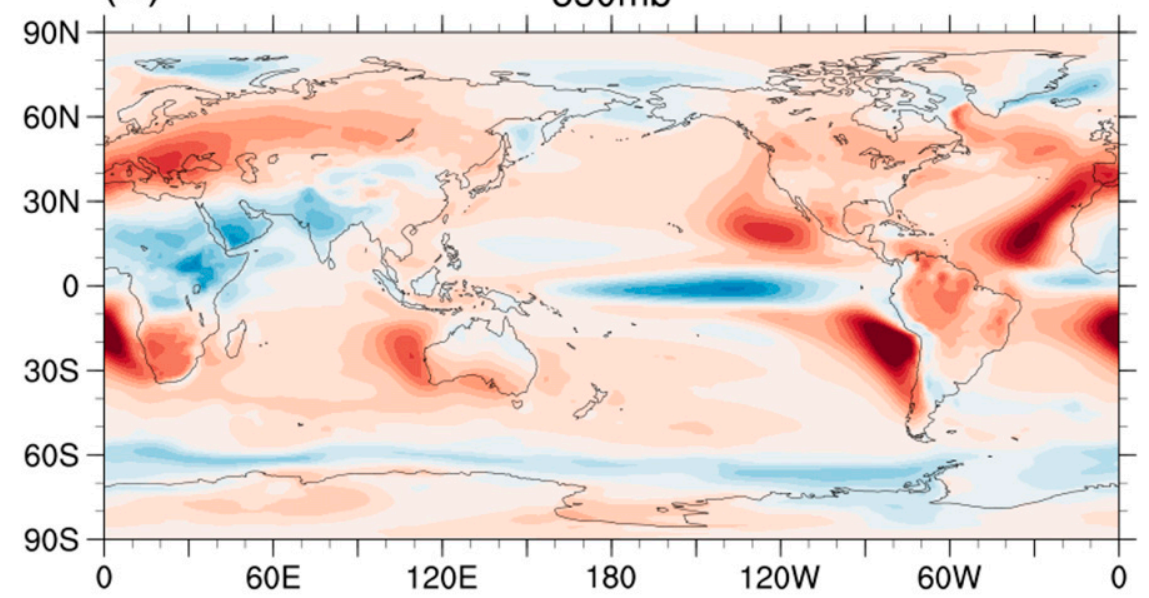

(b)

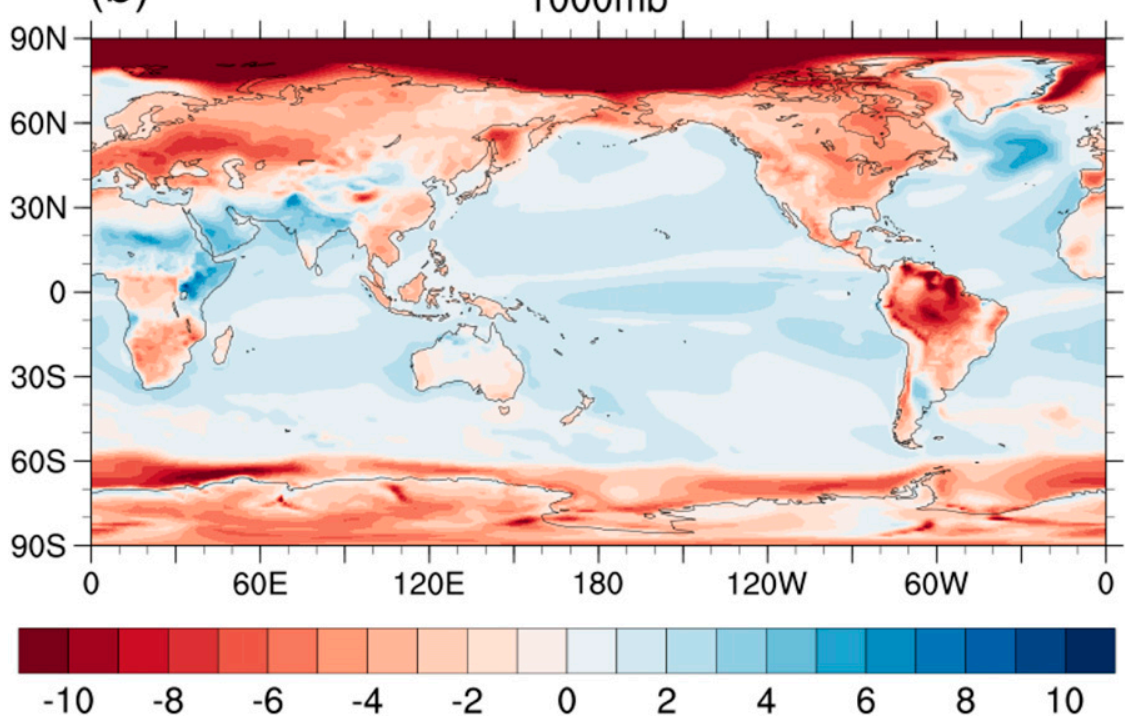

FIG. 12. Averaged composites of relative humidity (\%) from CESM1 simulations for 2050-80 minus $1920-50$ at levels of 850 and $1000 \mathrm{mb}$, respectively.

The results support an argument that the record-setting May 2015 rains over TX/OK could only have occurred in a climate that was conditioned by El Niño. Our hypothesis that El Niño was a necessary condition for such rains to occur over TX/OK in May 2015 is thereby affirmed.

Using the same ensemble simulations, we formed time slice analyses for early-twentieth-century and recentpast conditions and examined how a century of climate change affected the El Niño-related teleconnection dynamics and its driving of extreme May rain occurrences over TX/OK. The results revealed that no material changes appear in the overall atmosphere dynamics during extreme TX/OK May rainfall, including the El Niño-related dynamics. Further diagnosis supported an argument that the observed May 2015 event was not made more intense or become more likely as a result of human-induced climate change over the past century. We thus reject the hypothesis that climate change has altered, to date, the effectiveness by which El Niñorelated teleconnection dynamics drive the region's extreme May rainfall probabilities.

We further examined climate change impacts by analyzing the CESM1 ensembles for their projections to the latter half of the twenty-first century under the RCP8.5 scenario of greenhouse gas emissions. The analysis of a third time slice (2050-80) revealed a statistically significant increase in El Niño-related extreme May rainfall over TX/OK. Thus, whereas human-induced climate change over the last century was found to not 
materially affect the region's May extreme rainfall statistics, the results indicate a doubling in the frequency of a 100-yr May rainfall event comparable to the prior record (of the recent past vintage) and a roughly $5 \%$ increase in the intensity for May events having a severity of 2015 by the latter half of the twenty-first century.

Concerning the projected future change in extreme rainfall associated with $\mathrm{El} \mathrm{Niño}$, the results indicate that despite some changes in the oceanic expression of El Niño in CESM1, no material transformation occurred in the teleconnection pattern over North America. Our result thus differs from that of Wang et al. (2015), who argue that there has been a detectable effect of anthropogenic global warming on the physical processes causing the extreme May 2015 rainfall event. Possible reasons for differing results are that the inferences drawn by Wang et al. were based on linear relations between ENSO and the region's mean precipitation. No assumptions of linearity were invoked in our study, and further we utilize extreme value analysis to specifically address event likelihoods for rainfall severities akin to that occurring in 2015.

While our results indicate that dynamical processes driving extreme May rainfall over TX/OK appear neither to have changed materially nor to be projected to change appreciably over coming decades, thermodynamic conditions nonetheless appear much more favorable for yielding more extreme rainfall. For instance, atmospheric precipitable water over TX/OK is projected to increase by about $23 \%$ by the late twentyfirst century compared to the twentieth century in CESM1. Yet, return levels for extreme rainfall events having a return period close to the 400-yr event of 2015 were found to increase only about $5 \%$. The latter increase matched the overall increase in May climatological rainfall, but was appreciably less than that implied by simple Clausius-Clapeyron scaling. It should also be noted that even a $23 \%$ increase in precipitable water in the future would not be sufficient to explain a rare event as extreme as occurred in 2015, for which an extreme meteorological condition would greatly contribute to the magnitude. High precipitable water alone does not exert a strong constraint for the occurrence of extreme monthly May rain events over TX/OK.

\section{b. Discussion}

When comparing the early twentieth century to the recent past and asking the question how climate change - to date-may have affected the extreme May 2015 TX/OK rainfall event, our model-based analysis indicates no appreciable change in the underlying

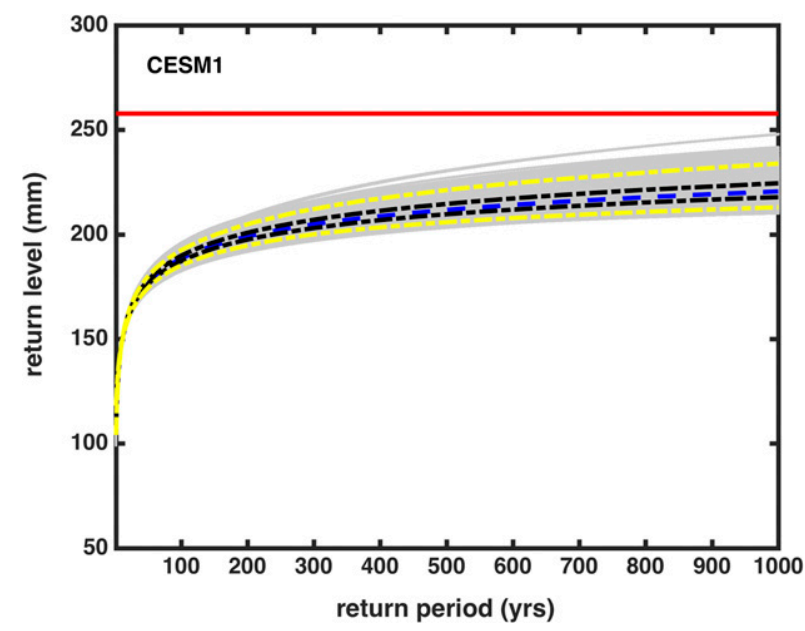

FIG. A1. Return level (mm) and return period (yr) estimations based on the exceedances above the $90 \%$ quantile of all the May rainfall of CESM1 simulations. Red line denotes the observed TX/ OK May 2015 rainfall. The gray lines are the return level ensembles calculated by combining 5000 samples from the posterior distributions of scale and shape parameters. The upper and lower black dashed lines, the blue dashed line, and the upper and lower yellow dashed lines quantify the $75 \mathrm{th}, 25 \mathrm{th}, 50 \mathrm{th}, 97.5 \mathrm{th}$, and 2.5 th percentiles of the return level ensembles, respectively.

physical relationship between extreme May rains and El Niño, involving its associated dynamical teleconnections [i.e., $\delta P(E \mid D) \approx 0$ ]. While the CESM1 results indicate some variation in the intensity and frequency of El Niño, there is an overall lack of agreement among models as to whether ENSO will materially change in response to increasing greenhouse gases, and furthermore owing to competing effects of different physical processes responsible for ENSO, the El Niño phenomenon is found to be relatively insensitive to doubled $\mathrm{CO}_{2}$ in most coupled models (e.g., Di Nezio et al. 2012). And, overall dynamics of atmospheric motions, to the extent those can be reasonably inferred from the vertical motion and its implied horizontal convergences that act to lift air masses and yield precipitation, showed no change to date (i.e., $\delta$ dynamic $\approx 0$ ). It might thus be reasonably surmised, given these indications for invariant dynamics, that simple thermodynamic considerations (i.e., $\delta$ thermodynamic) would have described the role of climate change in the extreme rainfall event of May 2015. Yet, the results indicated that threshold values of extreme rainfall actually increase much less than does the human-induced rise in column precipitable water, disagreeing with expectations based upon a simple Clausius-Clapeyron thermodynamic relation.

It should be noted that a Clausius-Clapeyron constraint on precipitation change related to climate 

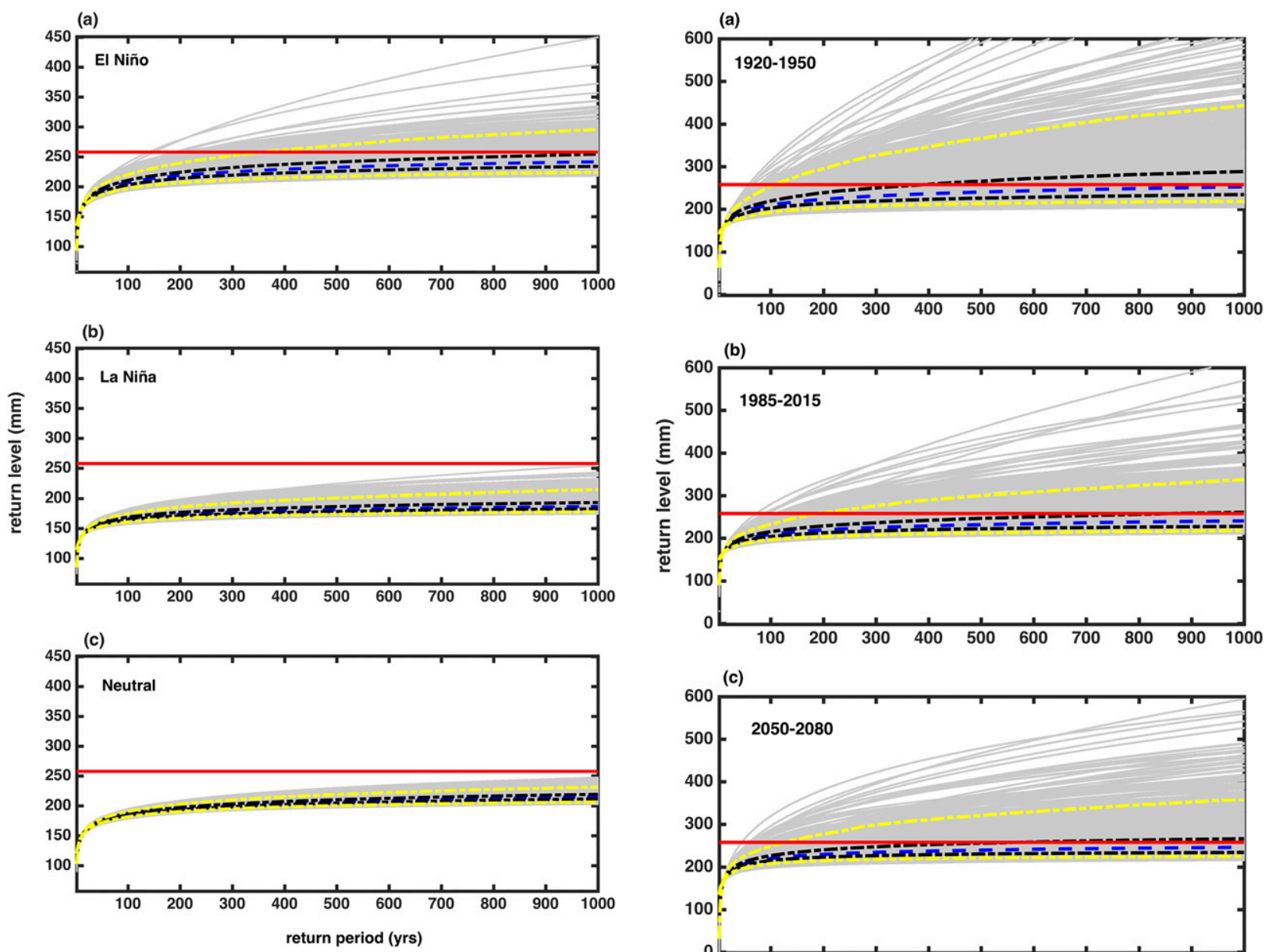

FIG. A2. Return level ( $\mathrm{mm}$ ) and return period (yr) estimations based on the exceedances above the $90 \%$ quantile of (a) El Niño, (b) La Niña, and (c) ENSO-neutral related May rainfall using CESM1 simulations. The red line denotes the observed TX/OK May 2015 rainfall. The gray lines are the return level ensembles calculated by combining 5000 samples from the posterior distributions of scale and shape parameters. The upper and lower black dashed lines, the blue dashed line, and the upper and lower yellow dashed lines quantify the 75th, $25 \mathrm{th}, 50 \mathrm{th}, 97.5 \mathrm{th}$, and 2.5 th percentiles of the return level ensembles, respectively.

change is stronger for daily extremes than for patterns of mean precipitation (e.g., Pall et al. 2007), and it is unclear whether constraints on monthly extremes studied herein should be more analogous to those of daily extremes or to mean changes. Concerning the 2015 event, this month-long deluge in nature was triggered by tremendous precipitation accumulated over the course of several very wet days. In this regard, it is not unrealistic to expect that a Clausius-Clapeyron relation would be a useful predictor for this extreme magnitude whose physical attributes are close to the statistics of daily precipitation extremes.

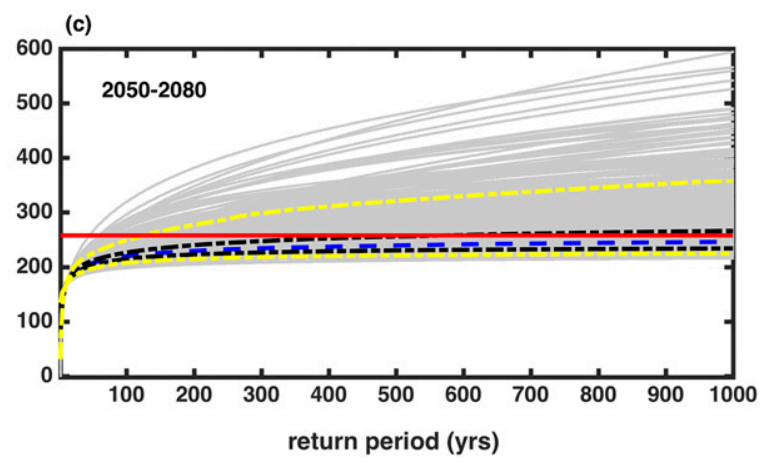

FIG. A3. Return level ( $\mathrm{mm}$ ) and return period (yr) estimations based on the exceedances above the $90 \%$ quantile of El Niñorelated May rainfall during (a) 1920-50, (b) 1985-2015, and (c) 205080 using CESM1 simulations. The red line denotes the observed TX/OK May 2015 rainfall. The gray lines are the return level ensembles calculated by combining 5000 samples from the posterior distributions of scale and shape parameters. The upper and lower black dashed lines, the blue dashed line, and the upper and lower yellow dashed lines quantify the 75th, 25th, 50th, 97.5th, and 2.5th percentiles of the return level ensembles, respectively.

However, a simplified narrative that solely depends upon thermodynamic considerations associated with increased column precipitable water, implicitly invoking a Clausius-Clapeyron argument for explaining the human-induced contribution to changes in extreme rainfall probabilities over TX/OK, would fail in this case using either May monthly or daily extremes. As mentioned previously, we have found that changes in May daily extreme rainfall over TX/OK also scaled appreciably less than Clausius-Clapeyron, consistent with the results of Sillman et al. (2013), who found no change by 


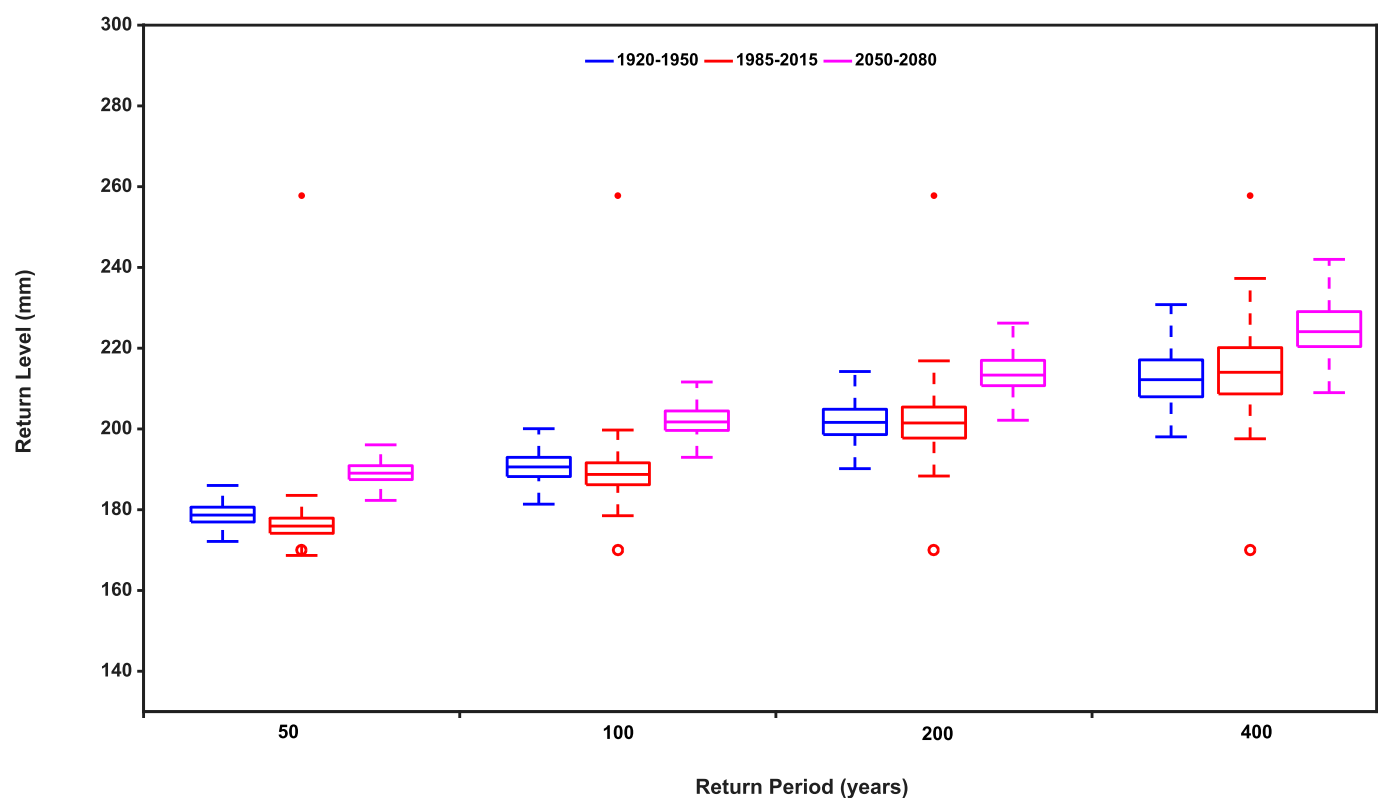

FIG. A4. Return level ( $\mathrm{mm}$ ) and return period (yr) estimations based on the exceedances above the $90 \%$ quantile of May rainfall during 1920-50 (blue), 1985-2015 (red), and 2050-80 (magenta) using CESM1 simulations. Box plots of distributions of return levels show the median (center mark) and the 25th (lower edge) and 75th (upper edge) percentiles, and the whiskers quantify the $95 \%$ credible interval. Red dots are the observed TX/OK May 2015 rainfall.

the end of the twenty-first century in warm season Rx5Day (monthly maximum consecutive 5-day precipitation) values over a region of central North America that includes our TX/OK region. This owes in part to the weak constraint between variations in precipitable water and the intensity of extreme rainfall, which was also discovered in a study of an extreme daily rainfall event during summer over Colorado (Hoerling et al. 2014).

In fact, our results indicate either that an absolute water vapor availability paradigm for thermodynamic driving of changes in extreme rains over TX/OK in May is too simple, in that the physical link is not deterministic, or that other important thermodynamic changes might also be operative. To the latter point, we note that boundary layer relative humidity $(1000-850 \mathrm{mb})$ decreases over most continental regions in the CESM1 experiments during May as low-level temperature rises more rapidly than does the absolute moisture content (Fig. 12). The CESM1 projections indicate that nearsurface relative humidity declines about $5 \%$ in $2050-80$ relatively to $1920-50$ over the TX/OK region. Observational analysis of land surface relative humidity trends during 1973-2013 show a decline of roughly $-3 \%$ (Willett et al. 2014), qualitatively consistent with the model simulations. Thus, dynamical driving that lifts large-scale air masses to their level of condensation must lift such air masses farther in the warmer climate compared to the early twentieth century (approximately an additional $100 \mathrm{~m}$; see Lawrence 2005). For a dry adiabatic lapse rate in the well-mixed boundary layer $\left[1^{\circ} \mathrm{C}(100 \mathrm{~m})^{-1}\right]$, air masses having $5 \%$ lower relative humidity would presumably reach saturation at a temperature that is $\sim 1^{\circ} \mathrm{C}$ cooler. The water vapor condensed at that level would likewise be less owing to the cooler temperature, thereby compensating for some of the absolute increase in column precipitable water.

An inference of the effectiveness of human-induced changes in dynamic and thermodynamic driving of changes in extreme rains can be made by estimating the regression coefficients of the two physical components in Eq. (4). Under the assumption of no change in underlying dynamics (i.e., $\delta$ dynamic $\approx 0$ ), in order to scale the $23 \%$ increase in water vapor content (i.e., $\delta$ thermodynamic $\approx 23 \%$ ) to the $5 \%$ increase in precipitation (return level) (i.e., $\delta E$ ) as projected in CESM1 by the end of the twenty-first century, the coefficient (i.e., $a_{2}$ ) of changes in thermodynamics is around 0.22 . Note that this value would have uncertainty given the weak correlation between column water and extreme rainfall. Notwithstanding, the inference is that roughly $22 \%$ of the moisture increase would be realized as an 

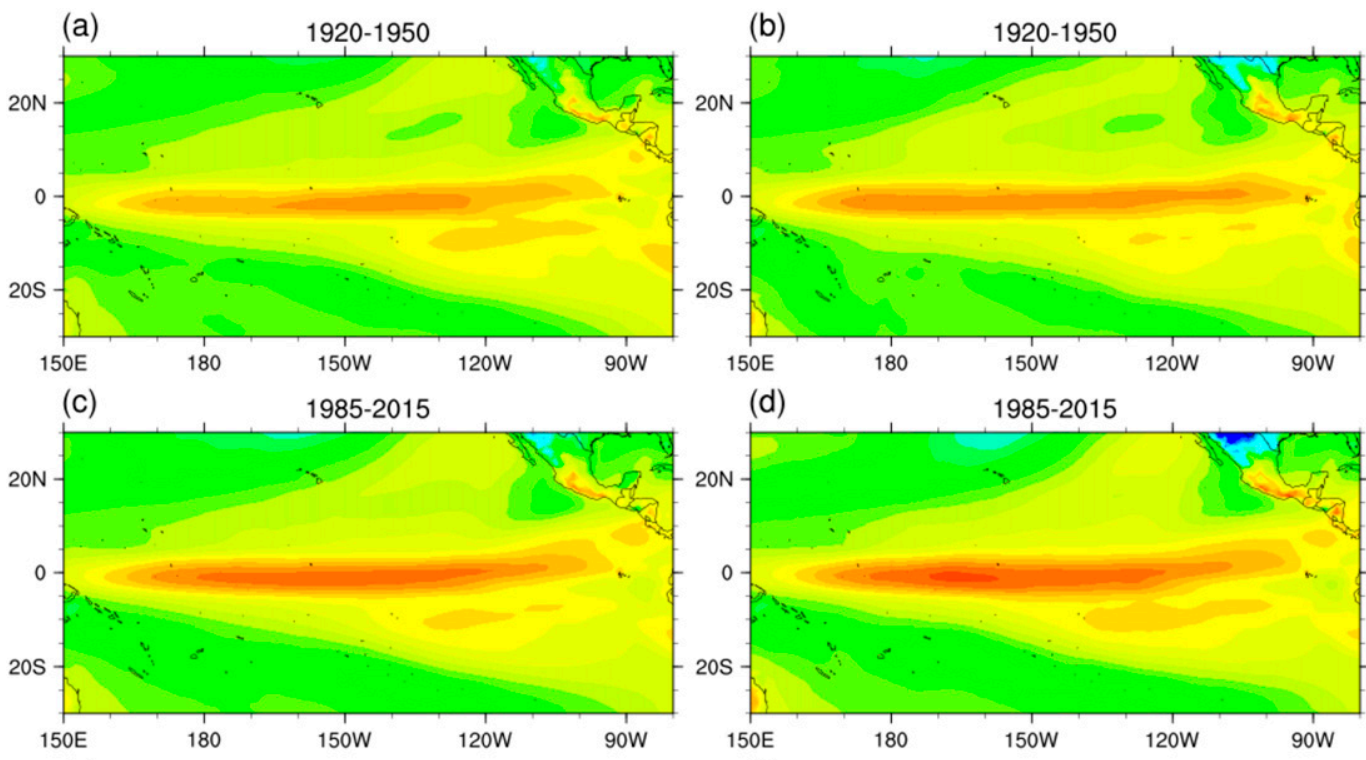

(d)

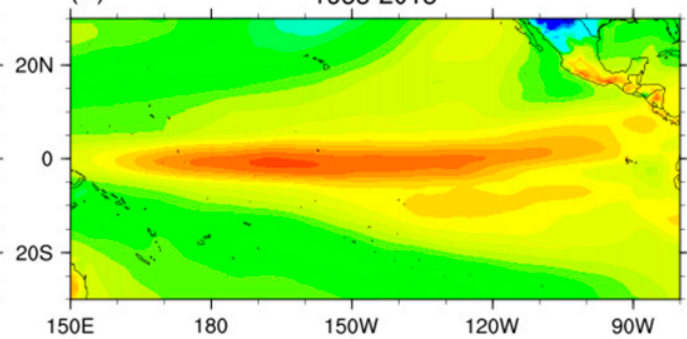

(e)

$2050-2080$
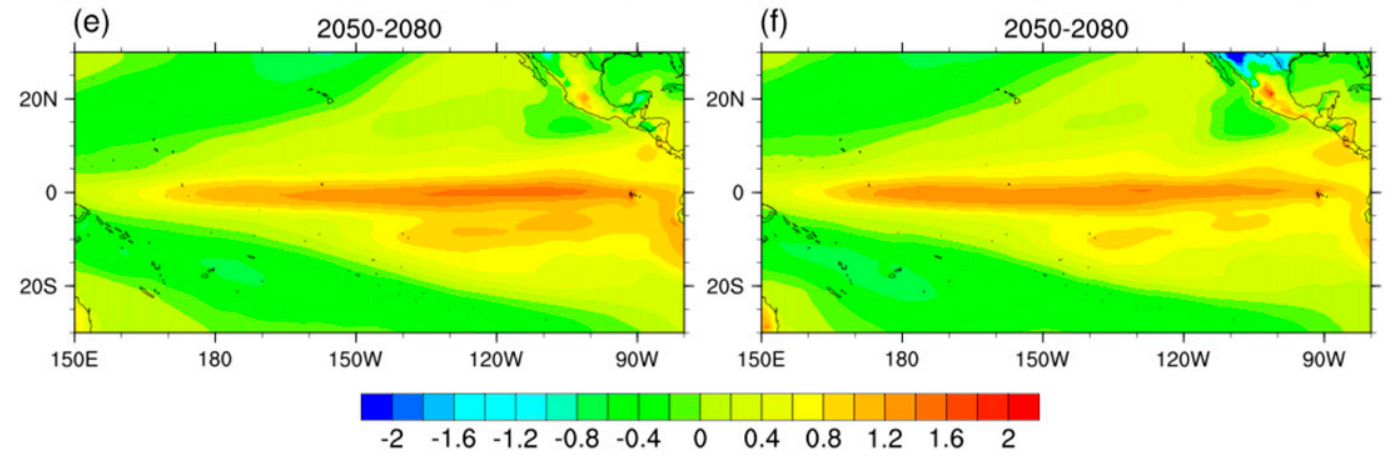

FIG. B1. Averaged composites of sea surface temperature anomalies $\left({ }^{\circ} \mathrm{C}\right)$ from CESM1 simulations based on (left) all El Niño events and (right) the wettest May El Niño events, i.e., top 10\% May El Niño events, relative to (a),(b) the historical period of 1920-50, (c),(d) the recent past period of 1985-2015, and (e),(f) the future period of 2050-80, respectively.

increase in the intensity of extreme rains. In other words, the effectiveness of the thermodynamic change related to rising column water is low in this scenario. Reasons for the low value of $a_{2}$ would include the presence of other competing thermodynamic factors, such as the decline in relative humidity identified herein.

The availability of large ensemble climate simulations facilitated a statistically robust estimate of changes in tail events, which is otherwise difficult from the short instrumental record alone. Our use of Bayesian inference in the diagnosis provided an estimate of uncertainty for distribution parameters and return levels simultaneously. We thereby concluded that, at $95 \%$ confidence level, our statistical estimates support an argument for the necessary role of El Niño in the occurrence of a rainfall magnitude as extreme as the 2015 event. Despite these strengths, we note that an event of the magnitude of May 2015 was exceedingly rare, and that even with the presence of El Niño the probability of occurrence remains very low. Despite the sampling benefits of large ensembles, the uncertainty in our assessments is nonetheless large. Further, all uncertainties were not considered (e.g., the dependency of results on different climate model simulations). Our model only represents one of the possible scenarios in response to climate forcings, although its overall mean climate sensitivity lies within the spread of CMIP5 multimodel simulations. Alternative models with different physical structures should be consulted for a comprehensive assessment of extreme event sensitivity to thermodynamic and dynamic drivers (Pfahl et al. 2017).

Despite having applied a quantitative approach to estimating changes in extreme rainfall events of the 
(a)

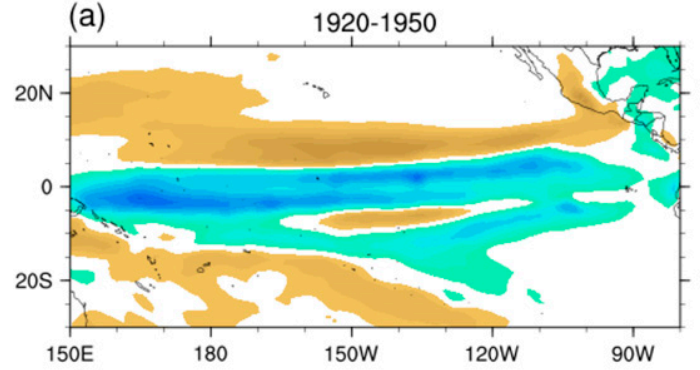

(c)

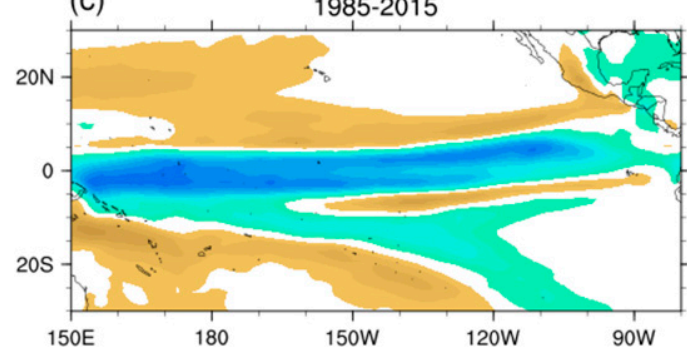

(e)

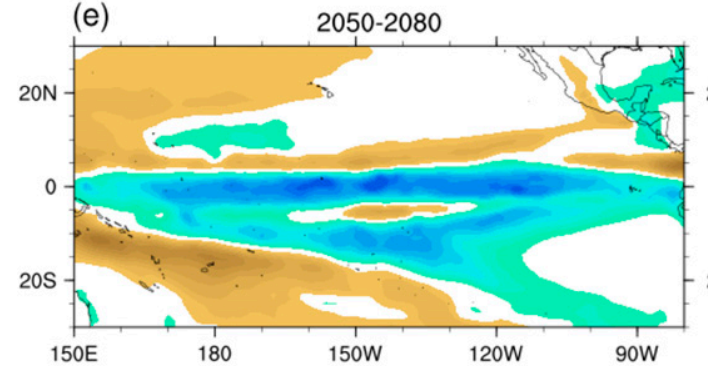

(b)

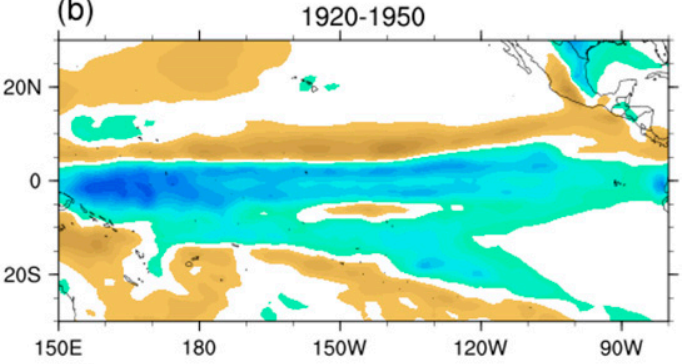

(d)

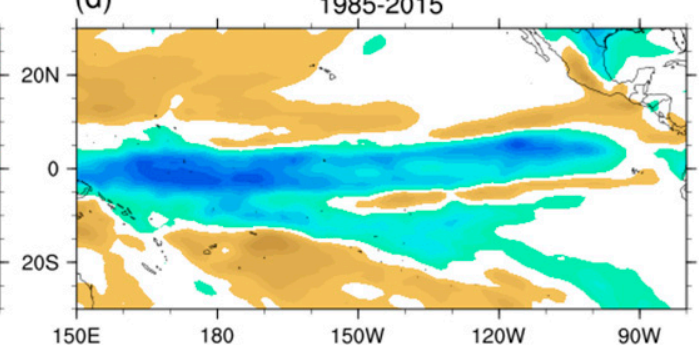

(f)

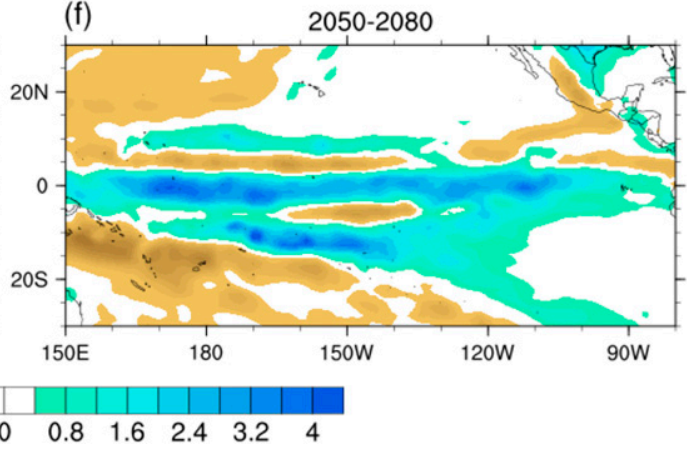

FIG. B2. Averaged composites of precipitation anomalies $\left(\mathrm{mm} \mathrm{day}^{-1}\right)$ from CESM1 simulations based on (left) all El Niño events and (right) the wettest May El Niño events, i.e., top 10\% May El Niño events, relative to (a),(b) the historical period of 1920-50, (c),(d) the recent past period of 1985-2015, and (e),(f) the future period of 2050-80, respectively.

type observed during May 2015 over TX/OK, our diagnosis of separate effects of dynamic and thermodynamic drivers was qualitative. Eventually, a parametric approach could be explored in order to better address and quantify dynamic and thermodynamic processes. Such methods would yield predictive information associated with the underlying factors. We also note that our conclusions are representative of the extreme rainfall behavior for the month of May, and for the TX/OK region only. Findings and results may vary in other regions and other seasons; thus, a global analysis should be explored. A comprehensive assessment on the role of anthropogenic contributions to El Niño-related extreme rainfall is warranted in order to test whether the invariance of El Niño-related dynamics linked to southern U.S. springtime extreme rainfall is also true for other teleconnection pathways such as tropical Walker circulation dynamics.

Acknowledgments. The authors acknowledge the support from NOAA's Climate Program Office MAPP program, and the support for this work provided by the PSD base support. The historical precipitation data used can be downloaded from http:// www.ncdc.noaa.gov/monitoring-references/maps/usclimate-divisions.php. The NCEP reanalysis derived data provided by NOAA/OAR/ESRL PSD are available at http://www.esrl.noaa.gov/psd/. The Hurrell SST data are from the NCAR CGD data archive: ftp.cgd. ucar.edu cd archive/SSTICE. The authors acknowledge the CESM Large Ensemble Community Project and supercomputing resources provided by NSF/CISL/ Yellowstone. 
(a)

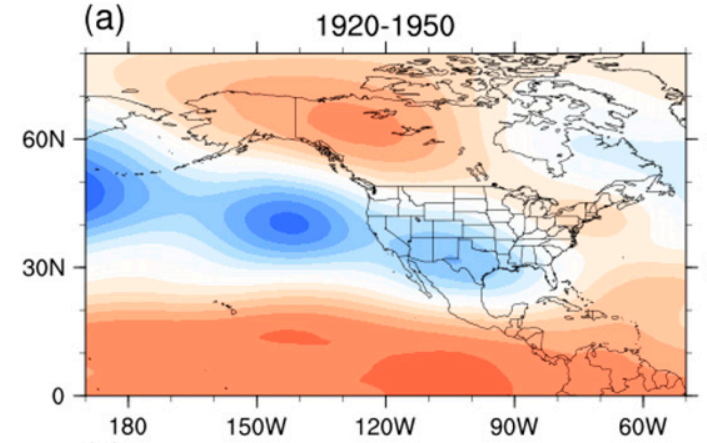

(c)

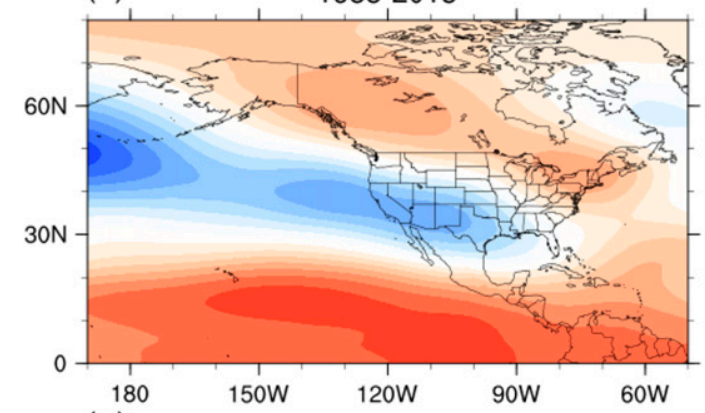

(e)

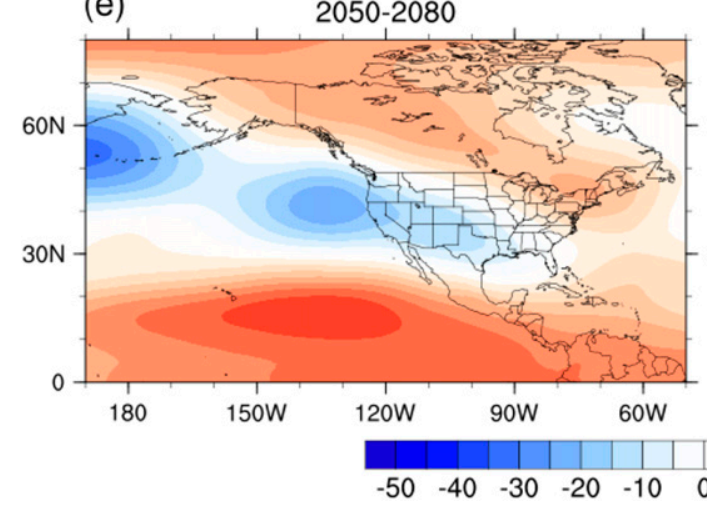

(b)

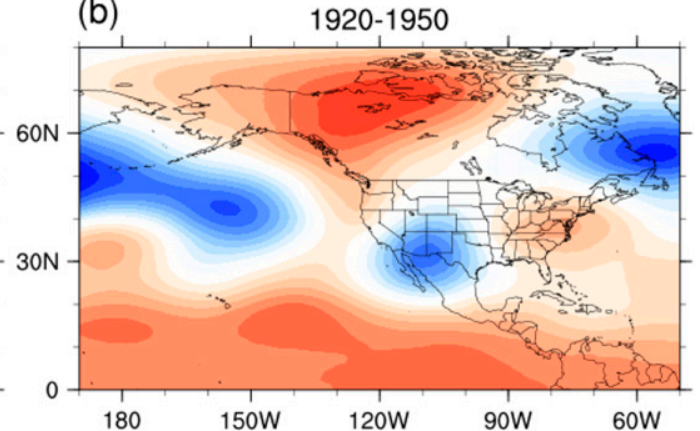

(d)

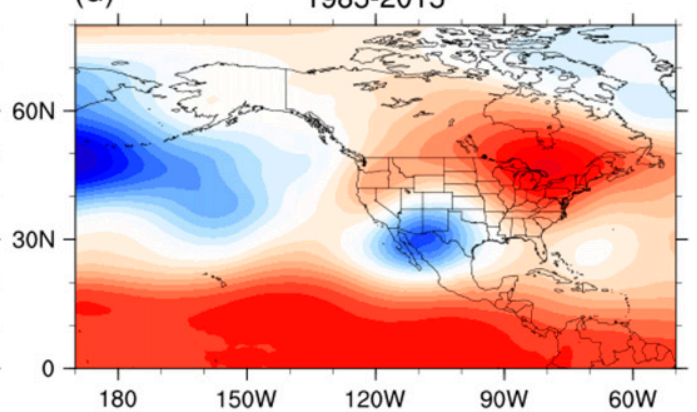

(f)

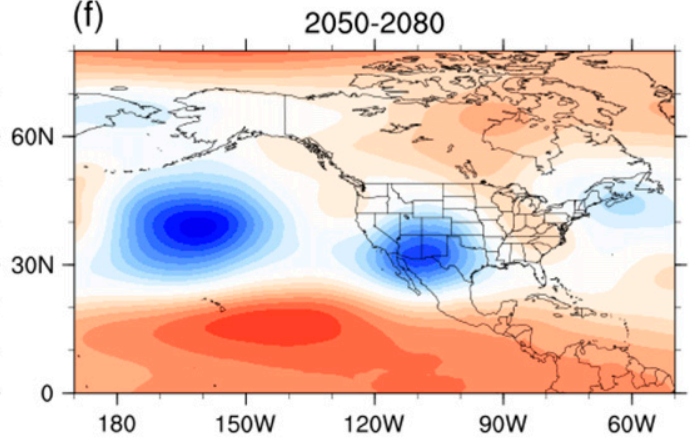

FIG. B3. Averaged composites of geopotential height anomalies (m) at $250 \mathrm{hPa}(\mathrm{Z} 250)$ based on (left) all El Niño events and (right) the wettest May El Niño events, i.e., top 10\% May El Niño events, relative to (a),(b) the historical period of 1920-50, (c),(d) the recent past period of 1985-2015, and (e),(f) the future period of 2050-80, respectively.

\section{APPENDIX A}

\section{Return Level (mm) and Return Period (year) Estimations for Extreme May Rainfall under Conditions}

Figures show the return level of extreme May rainfall 1) without other conditions (Fig. A1), 2) under ENSO conditions (Fig. A2), 3) under the presence of El Niño for the historical, recent past and future periods (Fig.
A3), and 4) for the historical, recent past and future periods (Fig. A4).

\section{APPENDIX B}

\section{Comparison between All EI Niño Events and The Wettest May El Niño Events}

Figures show the averaged composites of sea surface temperature anomalies (Fig. B1), precipitation anomalies 
(Fig. B2), and geopotential height anomalies (Fig. B3) for the historical, recent past, and future periods.

\section{REFERENCES}

Bjerknes, J., 1969: Atmospheric teleconnections from equatorial Pacific. Mon. Wea. Rev., 97, 163-172, https://doi.org/10.1175/ 1520-0493(1969)097<0163:ATFTEP $>2.3 . C O ; 2$.

Cai, W., and Coauthors, 2015: ENSO and greenhouse warming. Nat. Climate Change, 5, 849-859, https://doi.org/10.1038/nclimate2743.

Cayan, D. R., K. T. Redmond, and L. G. Riddle, 1999: ENSO and hydrologic extremes in the western United States. J. Climate, 12, 2881-2893, https://doi.org/10.1175/1520-0442(1999)012<2881: EAHEIT >2.0.CO;2.

Christidis, N., and P. A. Stott, 2015: Extreme rainfall in the United Kingdom during winter 2013/14: The role of atmospheric circulation and climate change [in "Explaining Extreme Events of 2014 from a Climate Perspective"]. Bull. Amer. Meteor. Soc., 96 (12), S46-S50, https://doi.org/10.1175/ BAMS-D-15-00094.1.

Collins, M., and Coauthors, 2010: The impact of global warming on the tropical Pacific Ocean and El Niño. Nat. Geosci., 3, 391-397, https://doi.org/10.1038/ngeo868.

DiNezio, P., B. Kirtman, A. Clement, S.-K. Lee, G. Vecchi, and A. Wittenberg, 2012: Mean climate controls on the simulated response of ENSO to increasing greenhouse gases. J. Climate, 25, 7399-7420, https://doi.org/10.1175/ JCLI-D-11-00494.1.

Dole, R., and Coauthors, 2011: Was there a basis for anticipating the 2010 Russian heat wave? Geophys. Res. Lett., 38, L06702, doi:10.1029/2010GL046582.

Gershunov, A., 1998: ENSO influence on intraseasonal extreme rainfall and temperature frequencies in the contiguous United States: Implications for long-range predictability. J. Climate, 11, 3192-3203, https://doi.org/10.1175/ 1520-0442(1998)011<3192:EIOIER > 2.0.CO;2.

, and T. P. Barnett, 1998: ENSO influence on intraseasonal extreme rainfall and temperature frequencies in the contiguous United States: Observations and model results. J. Climate, 11, 1575-1586, https://doi.org/10.1175/ 1520-0442(1998)011<1575:EIOIER > 2.0.CO;2.

Grimm, A., and R. Tedeschi, 2009: ENSO and extreme rainfall events in South America. J. Climate, 22, 1589-1609, https:// doi.org/10.1175/2008JCLI2429.1.

Hannart, A., J. Pearl, F. Otto, P. Naveau, and M. Ghil, 2016: Causal counterfactual theory for the attribution of weather and climate related events. Bull. Amer. Meteor. Soc., 97, 99-110, https://doi.org/10.1175/BAMS-D-14-00034.1.

Haylock, M. R., and Coauthors, 2006: Trends in total and extreme South American rainfall 1960-2000 and links with sea surface temperature. J. Climate, 19, 1490-1512, https://doi.org/ 10.1175/JCLI3695.1.

Herring, S. C., M. P. Hoerling, J. P. Kossin, T. C. Peterson, and P. A. Stott, 2015: Explaining extreme events of 2014 from a climate perspective. Bull. Amer. Meteor. Soc., 96, S1-S172, https:// doi.org/10.1175/BAMS-ExplainingExtremeEvents2014.1.

Hoerling, M. P., A. Kumar, and M. Zhong, 1997: El Niño, La Niña, and the nonlinearity of their teleconnections. J. Climate, $\mathbf{1 0}$, 1769-1786, https://doi.org/10.1175/1520-0442(1997)010<1769: ENOLNA $>2.0 . \mathrm{CO} ; 2$.

— and Coauthors, 2013: Anatomy of an extreme event. J. Climate, 26, 2811-2832, https://doi.org/10.1175/JCLI-D-12-00270.1.
K. Wolter, J. Perlwitz, X. Quan, J. Eischeid, H. Wang, S. Schubert, H. Diaz, and R. Dole, 2014: Northeast Colorado extreme rains interpreted in a climate change context [in "Explaining Extreme Events of 2013 from a Climate Perspective"]. Bull. Amer. Meteor. Soc., 95 (9), S15-S18, https:// doi.org/10.1175/1520-0477-95.9.S1.1.

Horel, J. D., and J. M. Wallace, 1981: Planetary-scale atmospheric phenomena associated with the Southern Oscillation. Mon. Wea. Rev., 109, 813-829, https://doi.org/ 10.1175/1520-0493(1981)109<0813:PSAPAW > 2.0.CO;2.

Hoskins, N. J., and D. J. Karoly, 1981: The steady linear response of a spherical atmosphere to thermal and orographic forcing. J. Atmos. Sci., 38, 1179-1196, https://doi.org/ 10.1175/1520-0469(1981)038<1179:TSLROA > 2.0.CO;2.

Hurrell, J. W., J. J. Hack, D. Shea, J. M. Caron, and J. Rosinski, 2008: A new sea surface temperature and sea ice boundary dataset for the Community Atmosphere Model. J. Climate, 21, 5145-5153, https://doi.org/10.1175/ 2008JCLI2292.1.

IPCC, 2013: Climate Change 2013: The Physical Science Basis. T. F. Stocker et al., Eds., Cambridge University Press, 1535 pp.

Kalnay, E., and Coauthors, 1996: The NCEP/NCAR 40-Year Reanalysis Project. Bull. Amer. Meteor. Soc., 77, 437-471, https:// doi.org/10.1175/1520-0477(1996)077<0437:TNYRP>2.0.CO;2.

Kay, J. E., and Coauthors, 2015: The Community Earth System Model (CESM) large ensemble project: A community resource for studying climate change in the presence of internal climate variability. Bull. Amer. Meteor. Soc., 96, 1333-1349, https://doi.org/10.1175/BAMS-D-13-00255.1.

Latif, M., and N. S. Keenlyside, 2009: El Niño/Southern Oscillation response to global warming. Proc. Natl. Acad. Sci. USA, 106, 20 578-20 583, https://doi.org/10.1073/pnas.0710860105.

Lawrence, M., 2005: The relationship between relative humidity and the dew point temperature in moist air: A simple conversion and applications. Bull. Amer. Meteor. Soc., 86, 225-233, https://doi.org/10.1175/BAMS-86-2-225.

Massey, N., and Coauthors, 2015: weather@home-Development and validation of a very large ensemble modeling system for probabilistic event attribution. Quart. J. Roy. Meteor. Soc., 141, 1528-1545, https://doi.org/10.1002/qj.2455.

Meehl, G. A., and H. Teng, 2007: Multi-model changes in El Niño teleconnections over North America in a future warmer climate. Climate Dyn., 29, 779-790, https://doi.org/10.1007/ s00382-007-0268-3.

National Academies of Sciences, Engineering, and Medicine, 2016: Attribution of Extreme Weather Events in the Context of Climate Change. National Academy Press, $186 \mathrm{pp}$.

NCDC, 2002: Time bias corrected divisional temperatureprecipitation-drought index: Documentation for dataset TD-9640. National Climatic Data Center, 12 pp., http:// www1.ncdc.noaa.gov/pub/data/documentlibrary/tddoc/td9640.pdf.

Pall, P., M. R. Allen, and D. A. Stone, 2007: Testing the ClausiusClapeyron constraint on changes in extreme precipitation under $\mathrm{CO}_{2}$ warming. Climate Dyn., 28, 351-363, https:// doi.org/10.1007/s00382-006-0180-2.

—, T. Aina, D. A. Stone, P. A. Stott, T. Nozawa, A. G. Hilberts, D. Lohmann, and M. R. Allen, 2011: Anthropogenic greenhouse gas contribution to flood risk in England and Wales in autumn 2000. Nature, 470, 382-385, https://doi.org/10.1038/ nature 09762

Perlwitz, J., M. Hoerling, J. Eischeid, T. Xu, and A. Kumar, 2009: A strong bout of natural cooling in 2008. Geophys. Res. Lett., 36, L23706, https://doi.org/10.1029/2009GL041188. 
Pfahl, S., P. A. O'Gorman, and E. M. Fischer, 2017: Understanding the regional pattern of projected future changes in extreme precipitation. Nat. Climate Change, 7, 423-427, doi:10.1038/ nclimate 3287.

Shepherd, T. G., 2014: Atmospheric circulation as a source of uncertainty in climate change projections. Nat. Geosci., 7, 703708, https://doi.org/10.1038/ngeo2253.

_ 2016: A common framework for approaches to extreme event attribution. Curr. Climate Change Rep., 2, 28-38, https:// doi.org/10.1007/s40641-016-0033-y.

Sillman, J., V. Kharin, F. Zwiers, X. Zhang, and D. Bronaugh, 2013: Climate extreme indices in the CMIP5 multimodel ensemble: Part 2. Future climate projections. J. Geophys. Res. Atmos., 118, 2473-2493, doi:10.1002/ jgrd.50188.

Timmermann, A., J. Oberhuber, A. Bacher, M. Esch, M. Latif, and E. Roeckner, 1999: Increased El Niño frequency in a climate model forced by future greenhouse warming. Nature, $\mathbf{3 9 8}$, 694-697, https://doi.org/10.1038/19505.

Trenberth, K. E., G. W. Branstator, D. Karoly, A. Kumar, N.-C. Lau, and C. Ropelewski, 1998: Progress during TOGA in understanding and modeling global teleconnections associated with tropical sea surface temperatures. J. Geophys. Res., 103, 14291-14324, https://doi.org/ 10.1029/97JC01444.
— J. Fasullo, and T. G. Shepherd, 2015: Attribution of climate extreme events. Nat. Climate Change, 5, 725-730, https:// doi.org/10.1038/nclimate2657.

Vautard, R., P. Yiou, F. Otto, P. Stott, N. Christidis, G. J. van Oldenborgh, and N. Schaller, 2016: Attribution of humaninduced dynamical and thermodynamical contributions to extreme weather events. Environ. Res. Lett., 11, 114009, https://doi.org/10.1088/1748-9326/11/11/114009.

Wang, S.-Y., W.-R. Huang, H.-H. Hsu, and R. R. Gillies, 2015: Role of the strengthened El Niño teleconnection in the May 2015 floods over the southern Great Plains. Geophys. Res. Lett., 42, 8140-8146, https://doi.org/10.1002/2015GL065211.

Webster, P. J., 1981: Mechanisms determining the atmospheric response to sea-surface temperature anomalies. J. Atmos. Sci., 38, 554-571, https://doi.org/10.1175/1520-0469(1981)038<0554: MDTART $>2.0 . \mathrm{CO} ; 2$.

Willett, K., A. Simmons, and D. Berry, 2014: [Global climate] Surface humidity [in "State of the Climate in 2013"]. Bull. Amer. Meteor. Soc., 95 (7), S19-S20, https://doi.org/10.1175/ 2014BAMSStateoftheClimate.1.

Xie, P., and P. A. Arkin, 1997: Global precipitation: A 17-year monthly analysis based on gauge observations, satellite estimates, and numerical model outputs. Bull. Amer. Meteor. Soc., 78, 2539-2558, https://doi.org/10.1175/1520-0477(1997)078<2539: GPAYMA $>2.0 . \mathrm{CO} ; 2$ 